\title{
The critical role of catalase in prooxidant and antioxidant function of p53
}

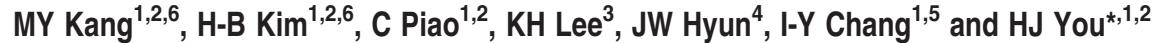

The tumor suppressor p53 is an important regulator of intracellular reactive oxygen species (ROS) levels, although downstream mediators of p53 remain to be elucidated. Here, we show that p53 and its downstream targets, p53-inducible ribonucleotide reductase (p53R2) and p53-inducible gene 3 (PIG3), physically and functionally interact with catalase for efficient regulation of intracellular ROS, depending on stress intensity. Under physiological conditions, the antioxidant functions of p53 are mediated by p53R2, which maintains increased catalase activity and thereby protects against endogenous ROS. After genotoxic stress, high levels of p53 and PIG3 cooperate to inhibit catalase activity, leading to a shift in the oxidant/antioxidant balance toward an oxidative status, which could augment apoptotic cell death. These results highlight the essential role of catalase in p53-mediated ROS regulation and suggest that the p53/p53R2-catalase and p53/PIG3-catalase pathways are critically involved in intracellular ROS regulation under physiological conditions and during the response to DNA damage, respectively.

Cell Death and Differentiation (2013) 20, 117-129; doi:10.1038/cdd.2012.102; published online 24 August 2012

Reactive oxygen species (ROS) are generated as products or by-products in cells and function as signaling molecules and cellular toxicants. ${ }^{1,2}$ Therefore, a series of antioxidant mechanisms maintain and protect intracellular redox homeostasis. ${ }^{2-4} \mathrm{~A}$ shift in the balance between oxidants and antioxidants toward oxidation causes DNA mutations, protein oxidation, and lipid peroxidation, which eventually lead to loss of molecular function ${ }^{1,2,5}$ and contribute to the pathogenesis of human diseases, including aging and cancer. $^{3}$

The $\mathrm{p} 53$ protein has been proposed as a critical regulator of intracellular ROS levels. Upon activation following DNA damage, p53 can activate several genes that result in increased ROS generation, which contributes to the induction of apoptosis in cells with unrepaired DNA damage. ${ }^{6-10}$ The induction of apoptosis is central to the tumor-suppressive activity of $p 53 .{ }^{11,12}$ By using the serial analysis of gene expression technique to evaluate the patterns of gene expression following p53 expression, a series of p53-inducible genes (PIG genes) have been identified that are predicted to encode proteins that could generate ROS. ${ }^{8}$ Of particular interest is p53-inducible gene 3 (PIG3), which shares sequence similarity with NADPH-quinine oxidoreductase, and is induced by p53 before the onset of apoptosis and contributes to ROS generation. ${ }^{8}$ Thus, PIG3 is believed to be one of the major factors involved in p53-induced apoptosis through ROS generation. This was the first clear connection between p53 and ROS generation, but the molecular mechanisms of PIG3-induced ROS generation have not yet been elucidated. Under physiological condition, basal levels of p53 can also upregulate antioxidant genes that function to lower ROS levels, and this antioxidant function of p53 is important in preventing oxidative stress-induced DNA damage and tumor development under low-stress conditions. ${ }^{13-21}$ Thus, p53 has opposing roles in the regulation of ROS, depending on the nature and intensity of the stress and on the cellular context. However, the precise molecular mechanisms of the balance between prooxidant and antioxidant states caused by p53 are not completely understood.

In this study we sought to identify cellular and molecular mechanism of p53-mediated positive and negative regulation of ROS generation. Our study reveals that $\mathrm{p} 53$ cooperating with PIG3 or p53-inducible ribonucleotide reductase (p53R2), p53 downstream targets, regulates ROS levels through upand downregulation of catalase activity.

\section{Results}

p53 and PIG3 directly bind with catalase. To clarify the molecular mechanisms of p53-mediated ROS regulation, a yeast two-hybrid screen was used to identify molecular partners of p53 and PIG3 implicated in the regulation of intracellular ROS levels. We isolated catalase, the antioxidant enzyme that defends against hydrogen peroxide $\left(\mathrm{H}_{2} \mathrm{O}_{2}\right),{ }^{5,22}$ by searching for new p53- and PIG3-interacting

${ }^{1}$ DNA Damage Response Network Center, Chosun University School of Medicine, Gwangju, South Korea; ${ }^{2}$ Department of Pharmacology, Chosun University School of Medicine Gwangju, South Korea; ${ }^{3}$ Department of Marine Life Science, College of Natural Sciences, Chosun University, Gwangju, South Korea; ${ }^{4}$ Department of Biochemistry, School of Medicine, Jeju National University, Jeju, South Korea and ${ }^{5}$ Department of Anatomy, Chosun University School of medicine, Gwangju, South Korea ${ }^{*}$ Corresponding author: HJ You, DNA Damage Response Network Center, Department of Pharmacology, Chosun University School of Medicine, 375 Seosuk-Dong, Gwangju, 501-759 Korea. Tel: +82 62230 6337; Fax: +82 62230 6586; E-mail: hjyou@chosun.ac.kr

${ }^{6}$ These authors contributed equally to this work.

Keywords: p53; reactive oxygen species; catalase; PIG3; p53R2

Abbreviations: PIG3, p53-inducible gene 3; p53R2, p53-inducible ribonucleotide reductase; ROS, reactive oxygen species; $\mathrm{H}_{2} \mathrm{O}_{2}$, hydrogen peroxide; BiFC, bimolecular fluorescence complementation

Received 23.4.12; revised 03.7.12; accepted 19.7.12; Edited by G Melino; published online 24.8.12 
proteins. To examine the interaction between endogenous p53 and catalase, cell extracts from U2OS and RKO cells were immunoprecipitated with the anti-catalase. Western blot analyses revealed that p53 was present in the immunoprecipitates obtained with anti-catalase antiserum, and that this interaction increased significantly after $\mathrm{H}_{2} \mathrm{O}_{2}$ or UV treatment (Figure 1a). To demonstrate the specificity of the catalase antibody, we created a catalase-deficient U2OS cell line using catalase-targeting small interference RNA and performed the co-immunoprecipitation in these cells. Immunoprecipitation of the catalase in catalase-knockdown cells treated with UV irradiation resulted in only a very faint band, indicating the specificity of this interaction (Figure $1 \mathrm{~b}$ ). Overexpression experiments in $\mathrm{H} 1299\left(\mathrm{p} 53^{-/}\right)$cells further confirmed that p53 specifically bound to catalase (Figure 1c).

To determine whether PIG3 interacts with catalase in a cell endogenously expressing PIG3 protein, cell extracts from RKO cells were immunoprecipitated with the anti-catalase antibody. Western blot analyses revealed that PIG3 was clearly present in the immunoprecipitates obtained with anticatalase antiserum, and this interaction increased after UV treatment (Figure 1d).

We next used purified recombinant proteins to test the possibility of a direct interaction of p53 and PIG3 to catalase. We premixed the purified human p53 or PIG3 with recombinant human catalase (Supplementary Figures 1a and b) and subjected the protein precipitates that we obtained to western blot assays using antibody specific to catalase. Immunoprecipitation with antibody to p53 pulled down catalase from the p53-catalase mixture (Figure 1e). Similarly, immunoprecipitation with antibody to PIG3 captured catalase from the PIG3catalase mixture (Figure 1f). These results suggest that p53 and PIG3 directly interacted with catalase.

p53 and PIG3 suppress catalase activity through association with catalase. The affinity of p53 and PIG3 for catalase described above prompted a search for a functional interaction between these proteins. Because p53 and PIG3 have no catalase activity (data not shown), the possibility that they may affect the enzymatic activity of catalase was investigated. Using recombinant purified human proteins, catalase activity was tested in the presence or absence of p53 and PIG3. Catalase activity was strongly and dose-dependently repressed by recombinant p53 (Figure 2a) and PIG3 (Figure 2b) protein. To further evaluate the role of p53 in the regulation of catalase function in vivo, we examined whether catalase is inhibited when p53 is overexpressed. Consistent with these in vitro results, ectopically expressed p53 decreased catalase activity in U2OS, RKO, and HCT116 cells (Figure 2c). Coincidently, p53-expressing cells showed increased ROS production (Figure 2d). However, we did not detect differences in the ROS levels between control and p53 expressing $\mathrm{H} 460$ cells (Figure 2d, lane 4). As H460 cells are deficient in catalase (Figure 2c, lane 4), p53 expression would likely fail to upregulate ROS production in catalase-deficient cells. Indeed, ectopic expression of p53 increased ROS levels in catalase-overexpressing $\mathrm{H} 460$ cells (Figure 2e) but not in catalase-depleted U2OS and RKO cells (Figure 2f), indicating that catalase is required for p53mediated $R O S$ regulation.
We next tested whether PIG3 expression influences catalase activity in p53-deficient cells. SW480 cells (p53 mutant), H1299 cells (p53 null), and HCT116 p53 ${ }^{-1-}$ cells were transiently transfected with either the PIG3 expression vector or its control vector, and catalase activity was measured. Ectopic expression of PIG3 reduced catalase activity and stimulated ROS production (Supplementary Figures $2 \mathrm{a}$ and b). Together, these results indicate that p53 and PIG3 suppress catalase activity in vitro and in vivo.

To identify the p53 region responsible for the interaction with catalase, we generated various fragments of V5-tagged human p53 and performed a series of co-immunoprecipitation experiments. We found that amino acid residues 301-393 in the C-terminus of p53 (P5) have a crucial role in the interaction with catalase (Figure 3a). Similarly, we generated expression constructs for a series of GFP-tagged PIG3 deletion mutants to identify the PIG3 domain responsible for the PIG3-catalase interaction. The immunoprecipitation results indicated that deletion of PIG3 residues 201-332 (PG3) abolished PIG3 binding to catalase (Figure $3 b$ ).

Catalase-binding region of p53 and PIG3 may inhibit catalase activity. If so, p53 mutants and PIG3 mutants that do not bind catalase should not affect catalase activity. The full-length p53 and P5 constructs, which retain the catalase interaction site, were able to suppress catalase activity (Figure 3c) and increase ROS levels (Figure 3d). In contrast, a region between amino acids 1 and 300 of p53 (P1), which does not bind catalase, only slightly affected catalase activity and ROS levels. Similarly, the expression of full-length PIG3 and PG5 reduced catalase activity (Figure $3 \mathrm{e}$ ) and increased ROS levels (Figure 3f), whereas a PIG3 mutant missing amino acids 201-332 (PG3) did not. Thus, the p53 and PIG3 region necessary for interacting with catalase is crucial for regulating catalase activity and ROS levels.

p53R2 mainly contributes to p53-mediated antioxidant function in physiological conditions. Previous studies have indicated that p53 knockdown increases ROS levels through the downregulation of antioxidant genes. ${ }^{14,17,20}$ The present study also confirmed that p53 knockdown in U2OS and RKO cells increased ROS production (Figure 4a). However, interestingly, p53 knockdown in HCT116 cells decreased ROS levels. p53 knockdown may differently modulate the expression of antioxidant genes in these cells, consequently altering ROS levels. However, the expression of antioxidant genes was comparable among p53-depeleted U2OS, RKO, and HCT116 cells (Supplementary Figure 3), indicating that the different patterns of ROS levels are not dependent on these antioxidants. In an effort to explain these observed differences in ROS levels, we examined the effect of p53 knockdown on catalase activity. Indeed, ROS levels were significantly inversely correlated with catalase activity in all three p53-depleted cell lines (Figures $4 a$ and b). Given that purified $\mathrm{p} 53$ protein inhibited catalase activity in vitro (Figure 2a) and that p53 overexpression reduced catalase activity in vivo (Figure 2c), p53 knockdown-dependent downregulation of catalase activity in U2OS and RKO cells (Figure $4 b$ ) is likely mediated by an additional factor. Catalase has been shown not to be regulated ${ }^{15}$ or upregulated $^{23}$ by $p 53$, and our data imply that p53 cannot 
a

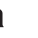

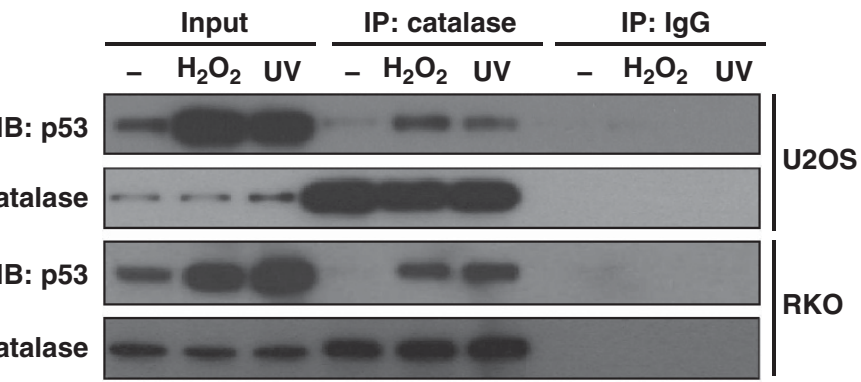

b

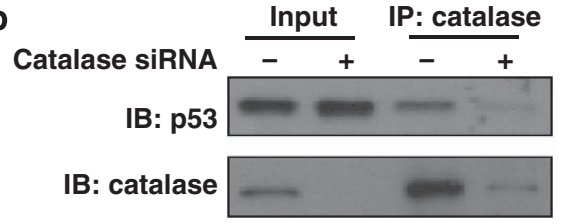

C

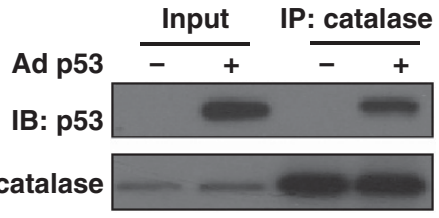

d

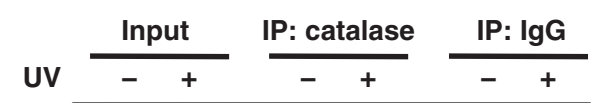

IB: PIG3

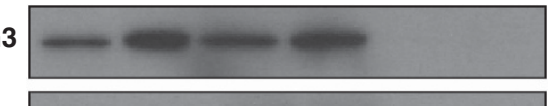

IB: catalase

e
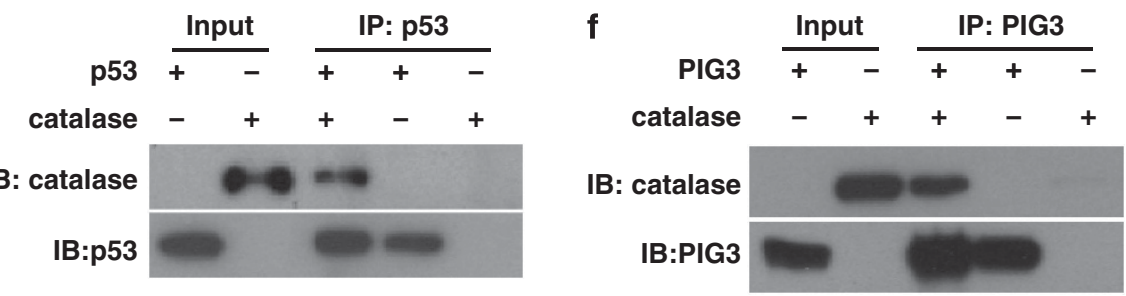

Figure 1 p53 and PIG3 interact with catalase. (a) U2OS and RKO cells were untreated or treated with $1 \mathrm{mM} \mathrm{H}_{2} \mathrm{O}_{2}$ or $20 \mathrm{~J} / \mathrm{m}^{2} \mathrm{UV}$. At $24 \mathrm{~h}$ after treatment, catalase was immunoprecipitated with anti-catalase antibody, and the immunoprecipitated proteins were detected with anti-p53 or anti-catalase antibodies. (b) U2OS cells were transfected with control or catalase siRNA. Immunoprecipitation and immunoblotting were performed $48 \mathrm{~h}$ post transfection, as indicated. (c) H1299 cells were infected with Ad-LacZ or Ad-p53. Immunoprecipitation and immunoblotting were performed $48 \mathrm{~h}$ post infection, as indicated. (d) RKO cells were untreated or treated with $20 \mathrm{~J} / \mathrm{m}^{2} \mathrm{UV}$ and lysed. Immunoprecipitation and immunoblotting were performed, as indicated. (e) Immunoprecipitation of human p53 from a mixture of p53 and catalase. The precipitates were subjected to western blotting using catalase antibody. The level of precipitated p53 was assessed with a human p53-specific antibody. (f) Immunoprecipitation of human PIG3 from a mixture of PIG3 and catalase. The precipitates were subjected to western blotting using catalase antibody. The level of precipitated PIG3 was assessed with a PIG3specific antibody

directly regulate catalase expression (Supplementary Figures 3 and 4).

p53R2 is a downstream target gene of $\mathrm{p} 53,,^{24,25}$ and microgram quantities of purified p53R2 protein exhibit catalase activity. ${ }^{26}$ Thus, p53R2 is a reasonable candidate for the p53-mediated upregulation of catalase activity under physiological conditions. However, microgram quantities of p53R2 protein are too high to be considered physiologically relevant. We found that $0.1-10.0 \mathrm{ng}$ of purified p53R2 protein, when incubated with purified catalase protein (Supplementary Figure 5), significantly and dose-dependently increased catalase activity (Figure 4c). While investigating how p53R2 regulates catalase activity, we found that p53R2 interacts with catalase in the presence or absence of UV irradiation (Figure 4d).

Overexpression experiments in HEK293T cells showed that the $36 \mathrm{C}$-terminal amino acids (R4) of p53R2 are required for the p53R2-catalase interaction (Figure 4e). Furthermore, wild-type p53R2 and R4 (residues 316-351), which retain the catalase interaction site, were able to increase catalase activity and reduce ROS levels (Supplementary Figures 6a and b). In contrast, a region comprising amino acids 1-206 of p53R2 (R2), which does not bind catalase, only slightly affected catalase activity and ROS levels. These data indicate that p53R2 increases catalase activity through a direct interaction with the enzyme.

To further explore the functional consequence of these interactions, we tested whether p53R2 depletion could affect catalase activity. Knockdown of p53R2 in U2OS and RKO cells reduced catalase activity and increased ROS levels (Supplementary Figures $7 \mathrm{a}$ and b), whereas only small changes occurred in p53R2-depeleted HCT116 cells. HCT116 cells contain mutated p53R2 (V115L), ${ }^{27}$ and we hypothesized that this mutant form of p53R2 may have no 

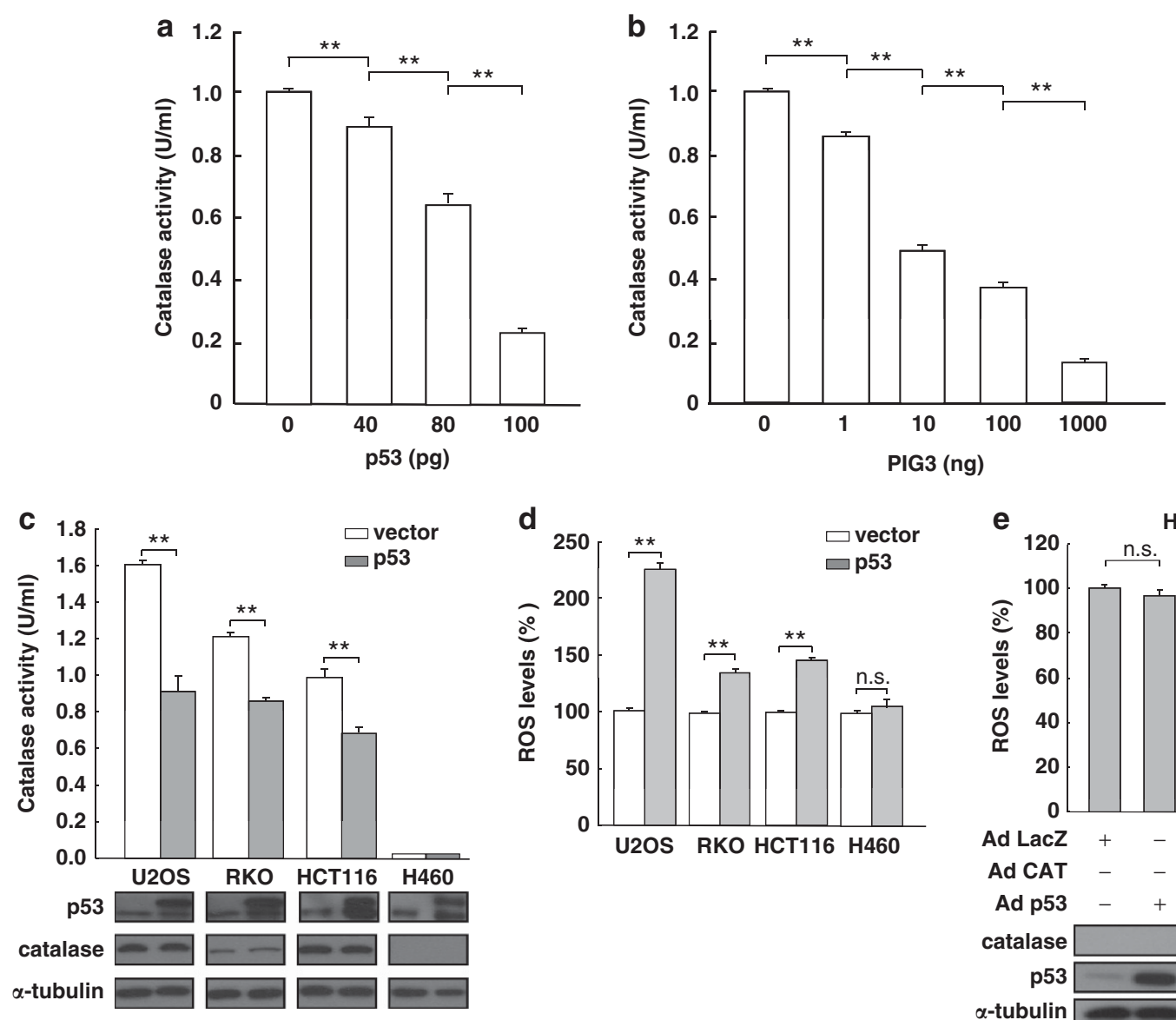

e $\mathrm{H} 460$

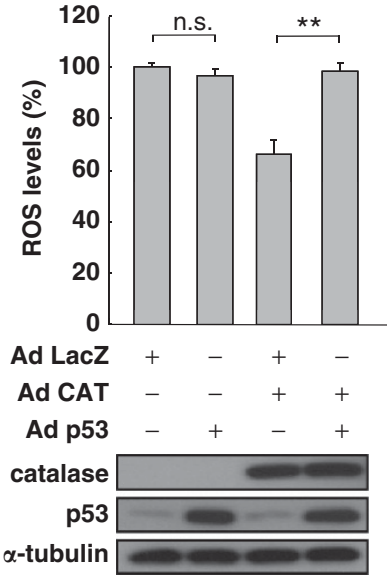

f
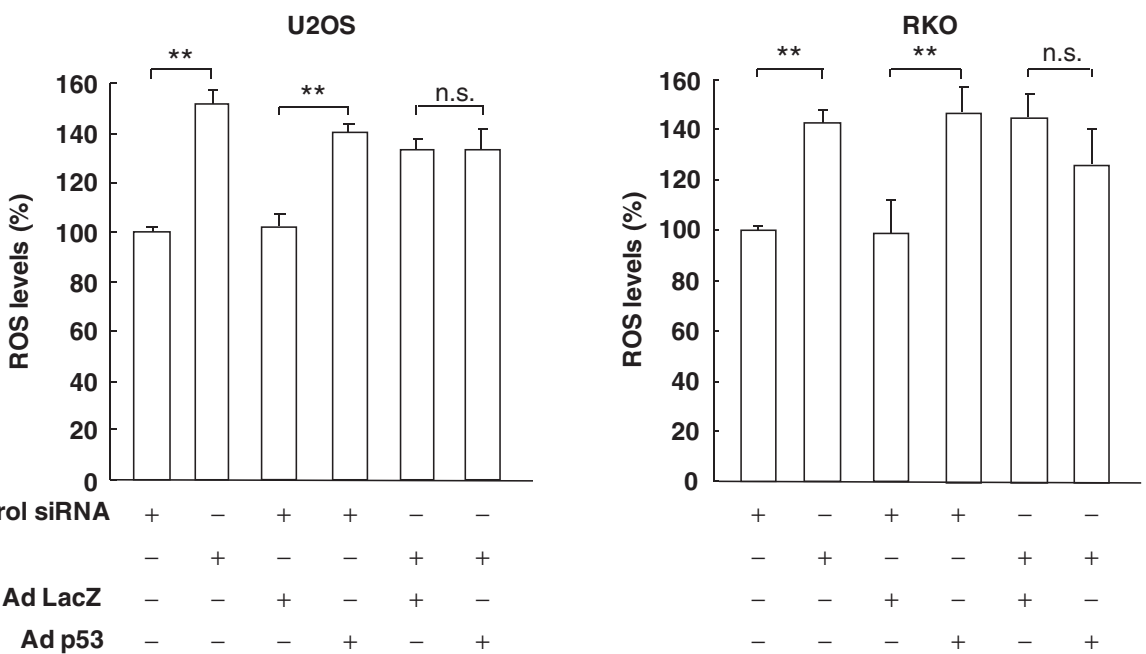

control siRNA
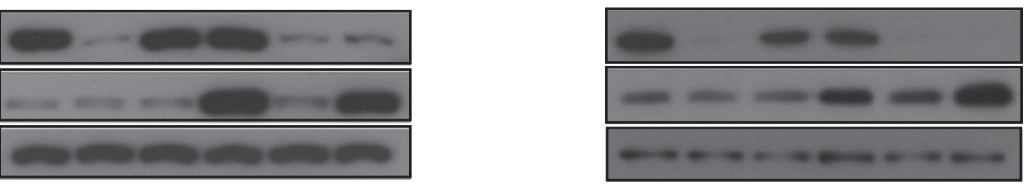
influence on catalase activity. We subsequently showed that wild-type p53R2, but not mutated p53R2 (V115L), increased catalase activity and suppressed ROS levels (Supplementary Figures $8 a$ and $b$ ).

We next investigated the effect of p53 knockdown on the p53R2-catalase interaction. Immunoprecipitation analyses revealed that the binding (Figure 4f) of catalase and p53R2 markedly decreased in p53-knockdown cells. Moreover, introducing p53R2 into p53-depleted cells restored catalase activity (Figure $4 \mathrm{~g}$ ) and ROS levels significantly decreased (Figure $4 \mathrm{~h}$ ). These results strongly suggest that wild-type p53R2 contributes to maintain increased catalase activity under unstressed conditions in p53-proficient cells.

Binding patterns of p53 and p53R2 to catalase. Because catalase localized mainly to the peroxisome, ${ }^{28}$ we examined the subcellular localization of p53, PIG3, p53R2, and catalase before and after UV irradiation. In unstressed cells, p53R2 and catalase localized in the peroxisomal fraction; however, p53 and PIG3 was very faint but predominantly peroxisomal-free supernatant fraction. In UV-stressed cells, the peroxisomal localizations of p53, PIG3, and p53R2 were increased (Supplementary Figure 9). Immunofluorescence analyses revealed that p53R2 but not p53 was colocalized with catalase in unstressed cells (Supplementary Figure 10). In contrast, both p53 and p53R2 colocalized with catalase after UV irradiation.

To further investigate the binding patterns of p53 and p53R2 to catalase in vivo, we performed a bimolecular fluorescence complementation (BiFC) assay using the fluorescent protein Venus, which enables visualization of direct protein interactions in living cells. ${ }^{29,30}$ To achieve this, we constructed various plasmids encoding the $\mathrm{N}$-terminal half (VN) or C-terminal half (VC) of Venus fused to the target proteins. U2OS cells co-transfected with VN-p53 and VCcatalase exhibited only a faint BiFC signal, which markedly increased after UV treatment (Figures $5 \mathrm{a}$ and $\mathrm{c}$ ). In contrast, cells co-transfected with VN-p53R2 and VC-catalase produced a strong BiFC signal that was not significantly affected by UV irradiation (Figures $5 b$ and $c$ ). To further dissect the kinetics of the dynamic changes in the binding of p53 and p53R2 to catalase in vivo, we conducted time-lapse BiFC imaging experiments in UV-irradiated living cells. The signal attributable to binding between p53 and catalase increased dramatically and became saturated about $2 \mathrm{~h}$ after UV irradiation, whereas the same experimental paradigm failed to alter the BiFC signal between p53R2 and catalase (Figures $5 \mathrm{~d}$ and $\mathrm{e})$. The mean value of the fluorescence intensity of cells further confirmed the kinetics of the dynamic changes in the binding activity between p53 and catalase in response to genotoxic stress (Figure 5f). These results strongly indicate that p53R2 efficiently interacts with catalase under unstressed conditions in vivo, whereas p53 binds catalase upon DNA damage.

p53 upregulates ROS generation through suppression of catalase activity in response to DNA damage. We next examined whether p53 influences catalase activity in response to DNA damage. We found that catalase activity significantly decreased in U2OS and HCT116 cells after UV treatment (Figure 6a) and ROS levels coincidently increased in these cells (Figure 6b). In contrast, catalase activity and ROS levels were only slightly affected in p53-deficient Saos-

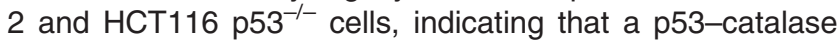
pathway is important for regulating DNA damage-induced ROS generation. To investigate the role of catalase in p53induced apoptosis, we examined the effect of catalase on UV-induced apoptosis. We found that catalase overexpression in U2OS cells significantly reduced UV-induced apoptosis (Supplementary Figures 11a and b). Because p53 overexpression in p53-null $\mathrm{H} 1299$ cells triggers apoptotic cell death in these cells, ${ }^{31} \mathrm{H} 1299$ cells stably transfected with control or catalase expression vectors were infected with Adp53, and apoptosis was examined. Catalase overexpression completely abolished the p53-induced generation of ROS in H1299 cells (Supplementary Figure 12). Notably, p53induced apoptotic sub-G1 DNA contents (Figure 6c) and active caspase-3/7 (Figure 6d) decreased significantly in catalase-overexpressing H1299 cells. Finally, using PIG3overexpressing p53 null cells, we examined whether catalase suppresses UV-induced apoptosis. We observed that the intracellular ROS formation was significantly increased in the

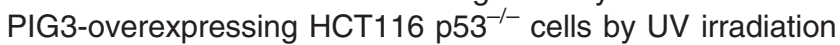
(Supplementary Figure 13). Importantly, PIG3-overexpressing cells infected with Ad-catalase underwent less apoptosis than those infected with the Ad-control vector after UV irradiation (Figures $6 \mathrm{e}$ and $\mathrm{f}$ ). Taken together, these data suggest that after DNA damage, p53 and PIG3 cooperate to trigger apoptosis by repressing catalase activity.

\section{Discussion}

Here, we demonstrate that p53 upregulates intracellular ROS levels through suppression of catalase activity: first, p53 and catalase can form a stable complex both in vitro and in vivo. Second, p53 protein is able to inhibit catalase activity in vitro. Third, cells that overexpress p53 exhibit lower catalase activity compared with that of control cells, indicating that p53 downregulates catalase activity in stressed cells, which have hyperphysiological levels of p53. Fourth, ectopic expression of p53 is not able to sufficiently increase ROS levels in catalase-deficient cells. Finally, PIG3, a key mediator

Figure 2 p53 and PIG3 repress catalase activity. (a and b) The indicated amount of recombinant human p53 (a) and PIG3 (b) protein were incubated with $1.0 \mathrm{U} / \mathrm{ml}$ of recombinant human catalase, and catalase activity was measured. (c and d) U2OS, RKO, HCT116, and H460 cells were transfected with control vector (white columns) or p53 expression vector (gray columns). At $48 \mathrm{~h}$ after transfection, catalase activity (c) and ROS levels (d) were measured. Cell lysates were analyzed by immunoblotting, as indicated (bottom). (e) p53 stimulates intracellular ROS generation in catalase-expressing $\mathrm{H} 460 \mathrm{Cells}$. $\mathrm{H} 460$ cells were infected with the indicated viral expression vectors for $48 \mathrm{~h}$, and then ROS production was assayed. Cell lysates were analyzed by immunoblotting, as indicated (bottom). (f) U2OS and RKO cells were transfected with control or catalase siRNA and then infected with Ad-LacZ or Ad-p53. At $24 \mathrm{~h}$ after infection, ROS generation was measured. Catalase and p53 levels were analyzed by immunoblotting (bottom). Results in a-f are shown as mean \pm S.E.M. $(n=3) .{ }^{* \star} P<0.01$ 
a

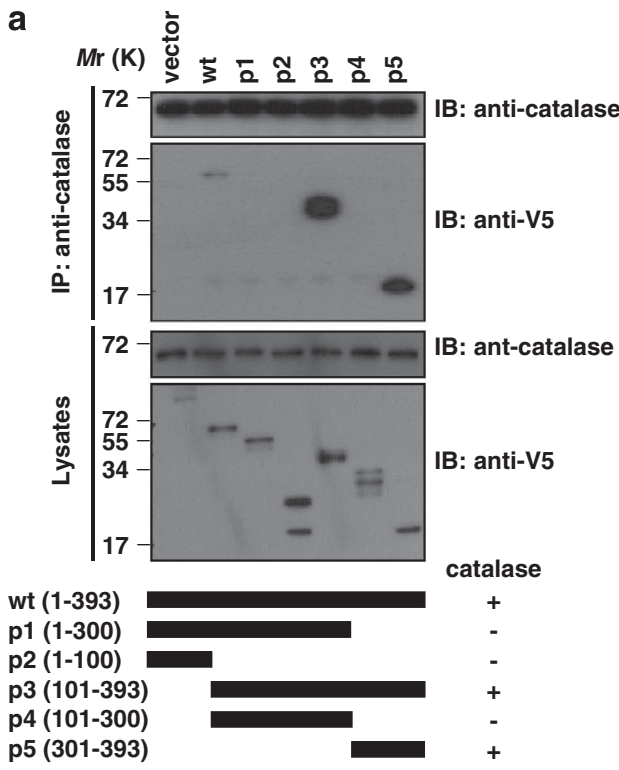

C

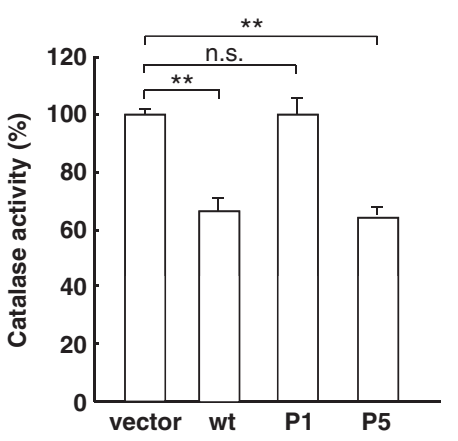

e

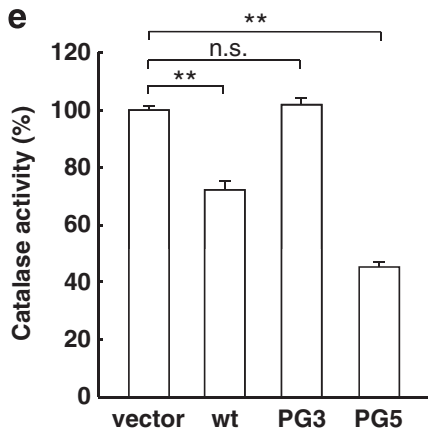

b
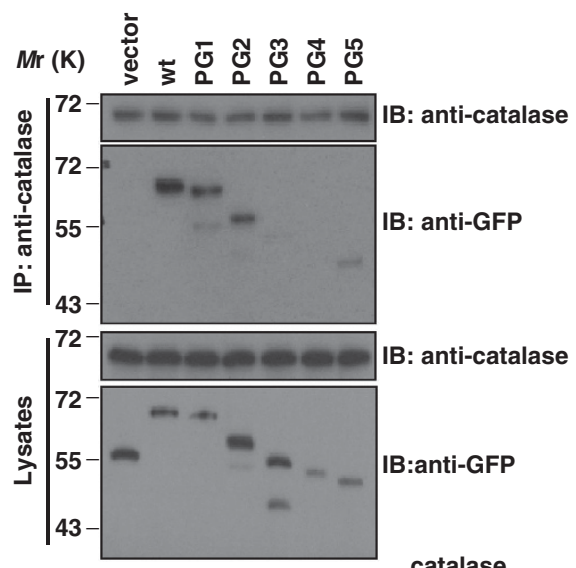

IB: anti-catalase

IB:anti-GFP

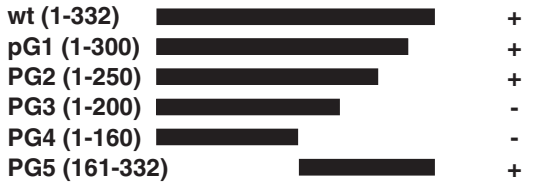

PG5 (161-332)
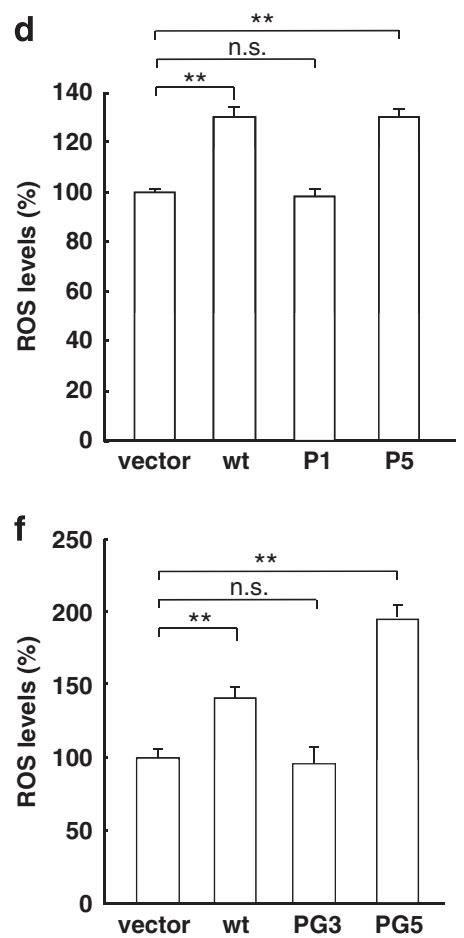

Figure 3 The C-terminal region of p53 and PIG3 is required for its interaction with catalase and upregulates ROS levels. (a) Plasmids encoding V5-tagged LacZ (vector), full-length p53 (wt) or deletion mutants of p53 were transfected into HEK293T cells. Catalase was immunoprecipitated with anti-catalase antibody, and the immunoprecipitated proteins were detected with anti-V5 antibody or anti-catalase antibody. (b) Lysates of HEK293T cells expressing the GFP control vector (vector), GFP-tagged full-length PIG3 (wt) or PIG3 deletion mutants were subjected to immunoprecipitation with anti-catalase, and the resulting precipitates were subjected to immunoblot analysis with anti-GFP or anti-catalase antibodies. Schematic presentation of the p53 and PIG3 deletion mutants used in the study (a and $\mathbf{b}$, bottom). The catalase binding properties of these p53 and PIG3 constructs are summarized. (c and d) Control plasmid (vector), plasmids encoding full-length p53 (wt) or p53 deletion mutants (P1 and P5) were transfected into H1299 cells. After $48 \mathrm{~h}$, catalase activity (c) and ROS levels (d) were measured. (e and f) Control plasmid (vector) or plasmids encoding full-length PIG3 (wt) or PIG3 deletion mutants (PG3 and PG5) were transfected into H1299 cells. After $48 \mathrm{~h}$, catalase activity (e) and ROS levels (f) were measured. Results in c-f are shown as mean \pm S.E.M. ( $n=3$ ). ${ }^{* *} P<0.01$

of p53-dependent ROS generation, also associates with catalase and inhibits catalase activity both in vitro and in vivo. This suggests that after genotoxic stress, high levels of p53 and PIG3 cooperate in cells to cause a strong inhibition of catalase activity, resulting in an increase in ROS generation. Collectively, the inhibition of catalase activity caused by p53 is probably the main prooxidant function of p53.

We found that the decreased catalase activity caused by p53 contributed substantially to p53-induced apoptosis. 

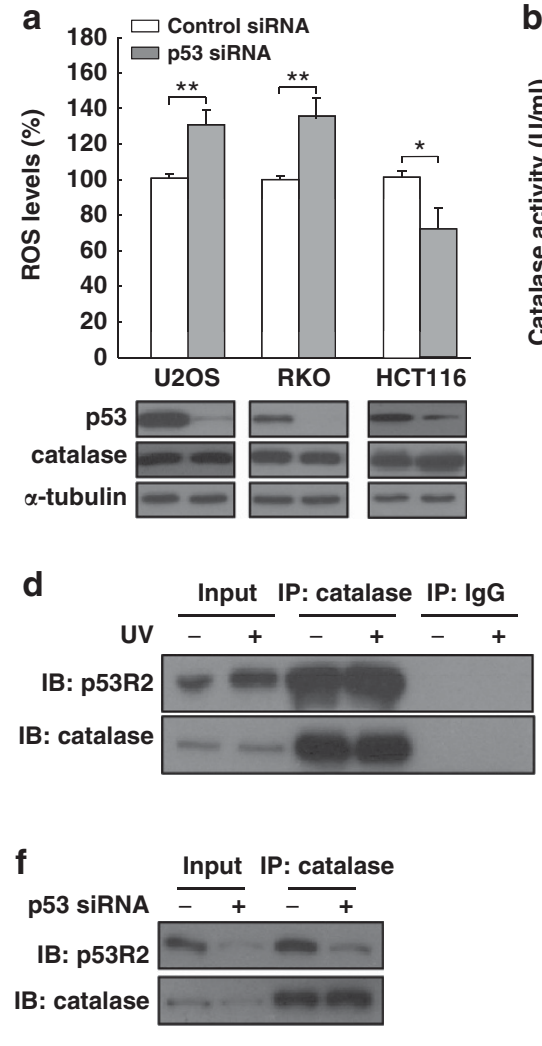
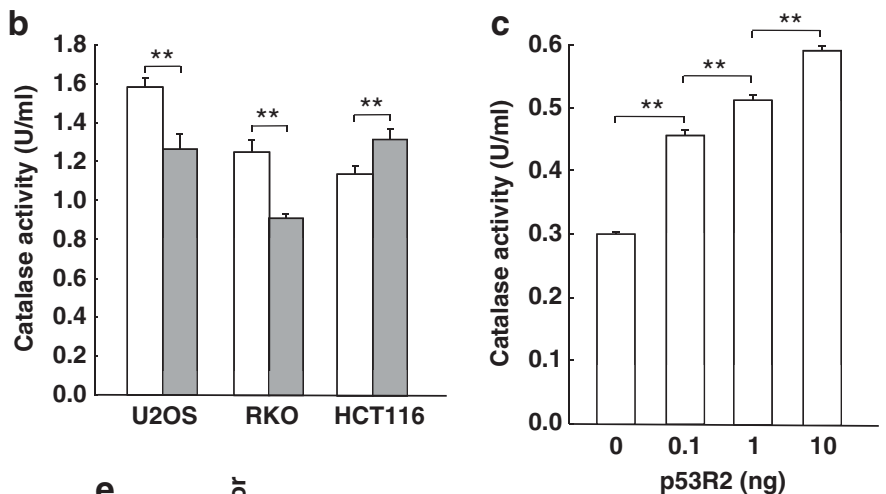
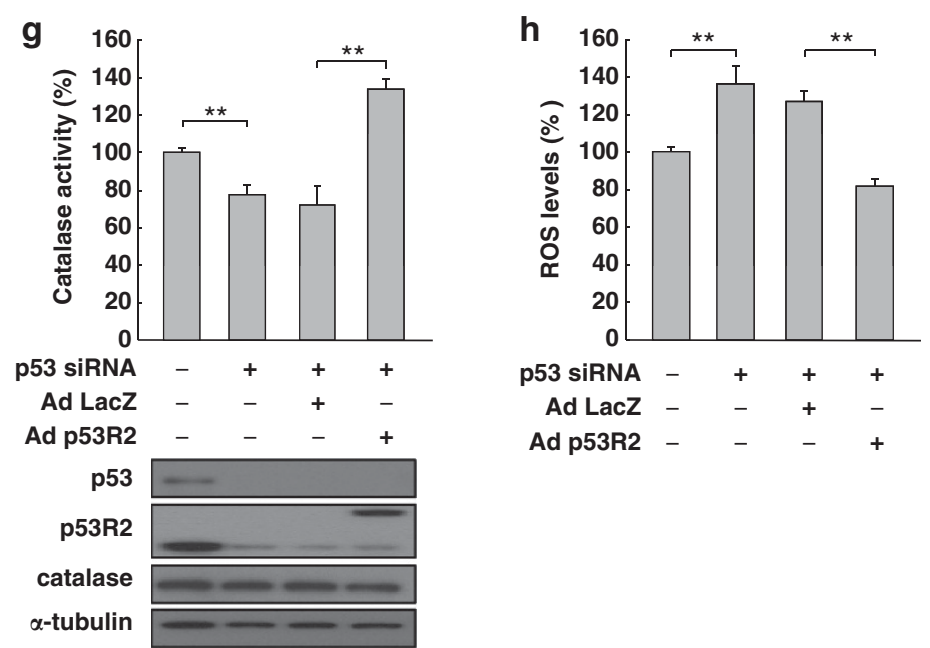

Figure 4 p53R2 interacts with catalase and is required for antioxidant function of p53. (a and $\mathbf{b}$ ) U2OS, RKO, and HCT116 cells were transfected with control (white columns) or p53 (gray columns) siRNA, and ROS levels (a) and catalase activity (b) were measured $48 \mathrm{~h}$ later. Cell lysates were analyzed by immunoblotting, as indicated (bottom). (c) Catalase activity was measured in reactions containing equal amounts of catalase $(0.3 \mathrm{U} / \mathrm{ml}$ ) and various amounts of p53R2 protein. (d) U2OS cells were untreated or treated with UV $\left(20 \mathrm{~J} / \mathrm{m}^{2}\right)$. At $24 \mathrm{~h}$ after irradiation, catalase was immunoprecipitated with anti-catalase antibody, and the immunoprecipitated proteins were detected with anti-p53R2 or anti-catalase antibodies. (e) Plasmids encoding GFP (vector), GFP-tagged full-length p53R2 (wt) or p53R2 deletion mutants were transfected into HEK293T cells. Immunoprecipitation and immunoblotting were performed $48 \mathrm{~h}$ post transfection, as indicated. Schematic presentation of p53R2 deletion mutants used in the study (bottom). The catalase binding properties of these p53R2 constructs are summarized. (f) U2OS cells were transfected with control or p53 siRNA. At $48 \mathrm{~h}$ after transfection, immunoprecipitation and immunoblotting were performed, as indicated. ( $\mathbf{g}$ and $\mathbf{h}$ ) U2OS cells were transfected with control or p53 siRNA and then infected with Ad-LacZ or Ad-p53R2. The cells were then analyzed for catalase activity (g) and ROS levels (h). Immunoblots of p53, p53R2, and catalase from transfected cells are shown (bottom). Results in $\mathbf{a}-\mathbf{c}, \mathbf{g}$ and $\mathbf{h}$ are shown as mean \pm S.E.M. $(n=3) .{ }^{\star \star} P<0.01,{ }^{*} P<0.05$

In response to DNA damage, catalase activity was suppressed significantly in p53-expressing cells, but not in p53deficient cells, causing an increase in intracellular ROS generation that allowed p53-induced apoptosis to occur. Notably, catalase protected p53-induced apoptosis through suppression of p53-induced ROS generation and inhibition of 
a

BiFC
(VN-p53/VC-Cat) $\quad$ VN-p53 $\quad$ vC-Catalase
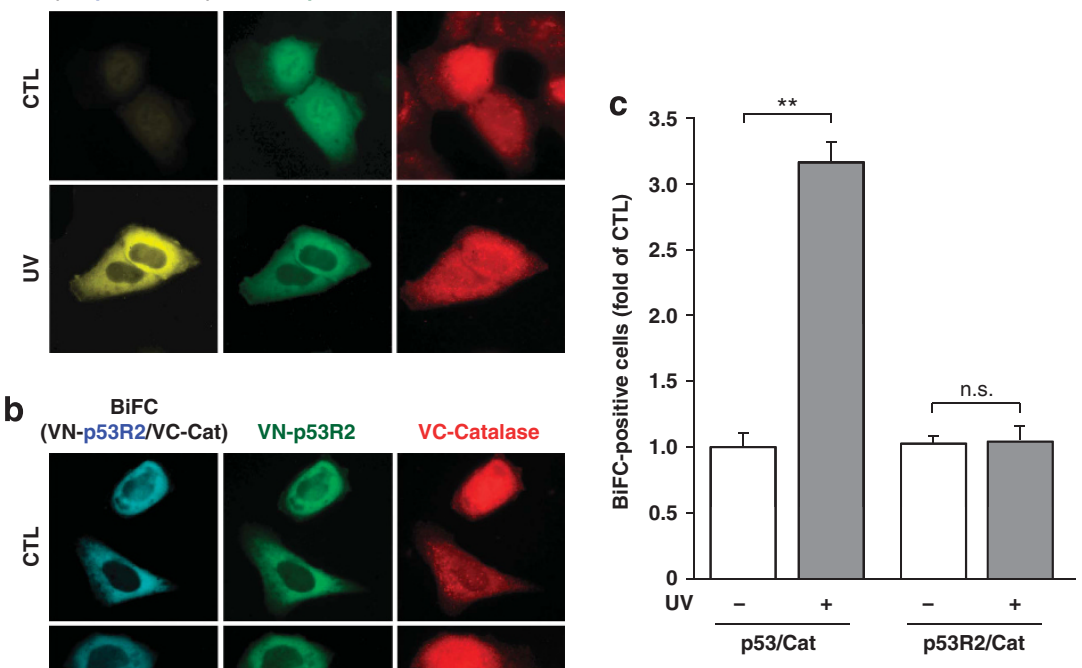

b $\underset{(\mathrm{VN}-\mathrm{p} 53 \mathrm{R} 2 / \mathrm{NC}-\mathrm{C}}{\mathrm{BiFC}}$

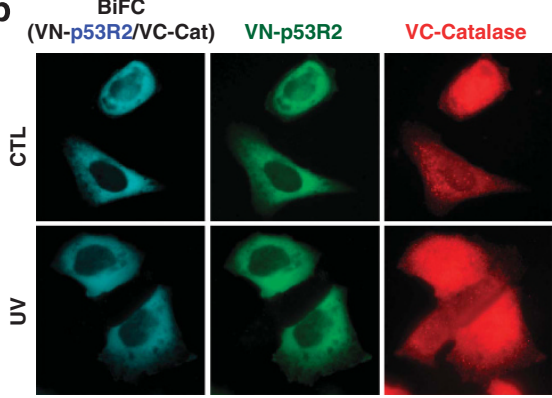

d

Time after UV treatment (min)
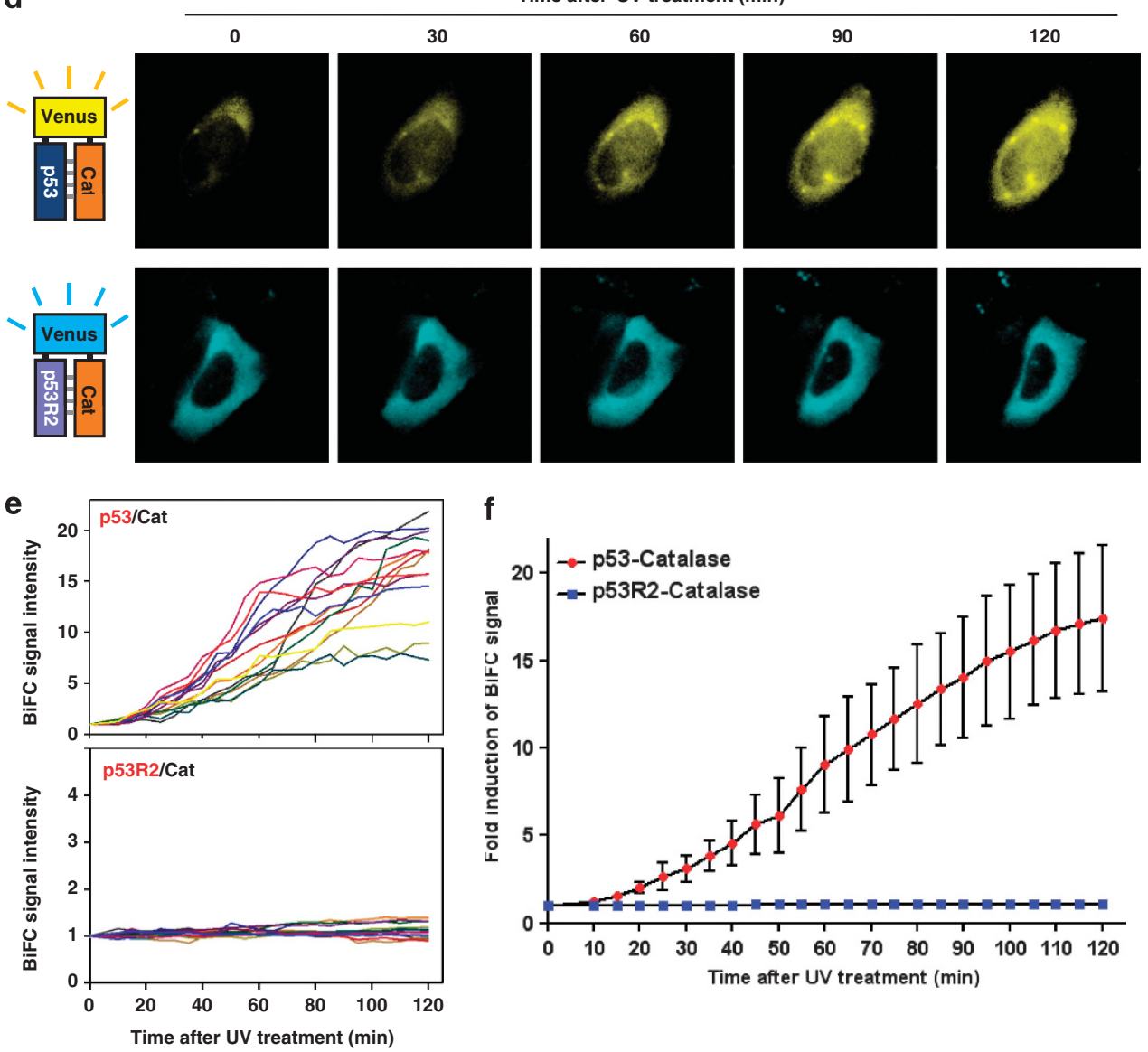

f

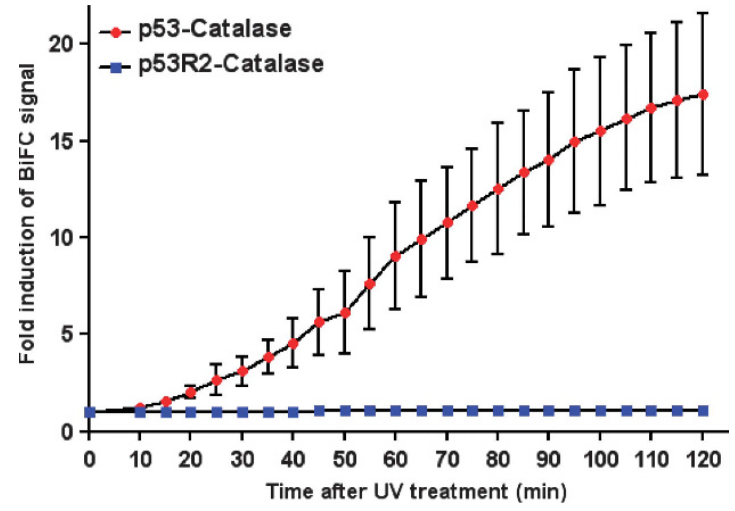



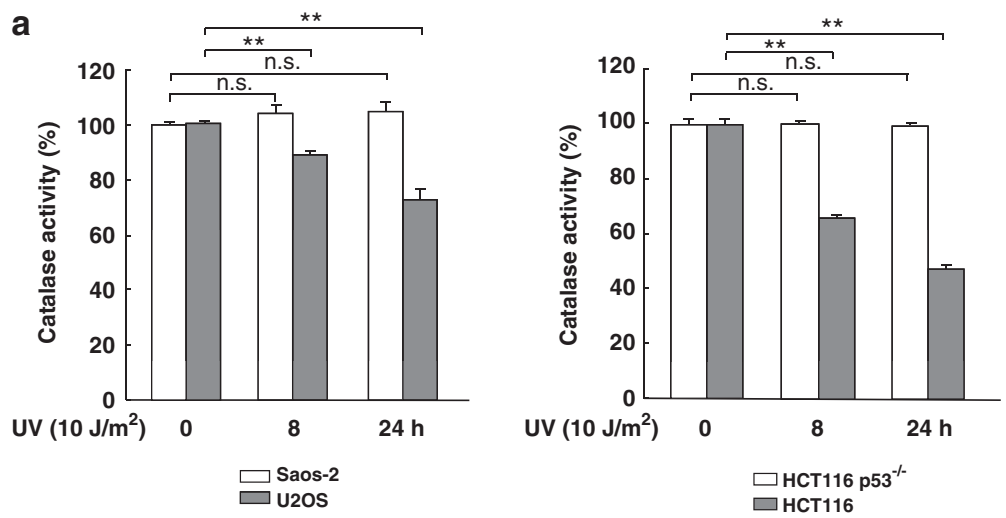

C
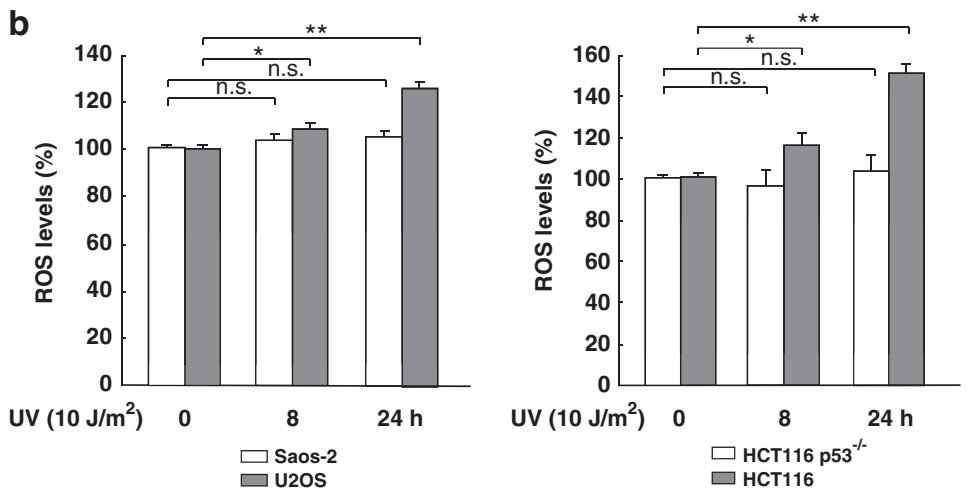

d
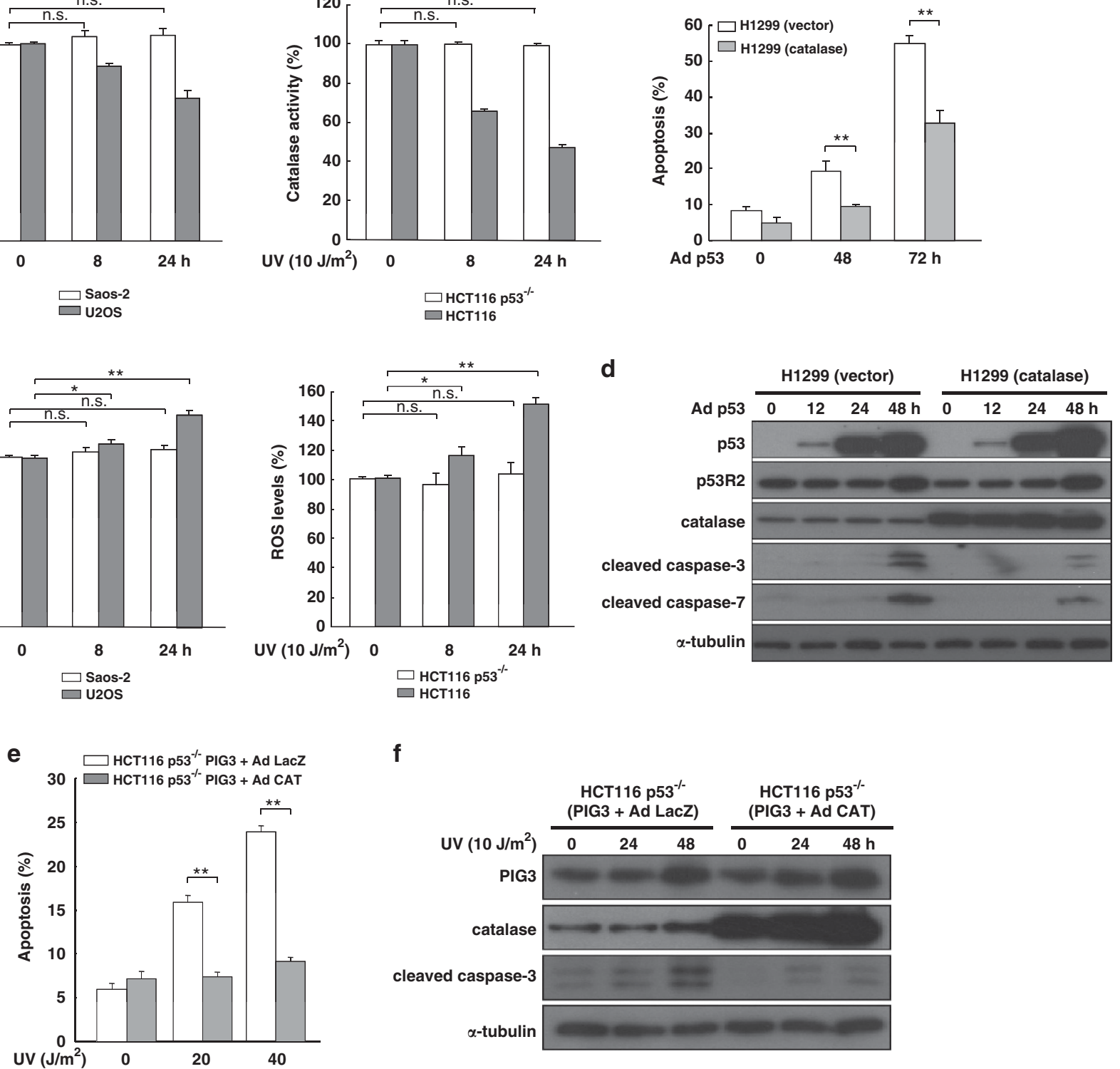

Figure 6 Catalase overexpression inhibits p53- and PIG3-induced apoptotic cell death (a and b) Saos-2 and U2OS cells (left panel) and HCT116 p53 ${ }^{-/-}$and HCT116 cells (right panel) were irradiated with $10 \mathrm{~J} / \mathrm{m}^{2} \mathrm{UV}$ for the indicated times, and catalase activity (a) and ROS levels (b) were measured. (c) Control (white columns) and catalaseoverexpressing (gray columns) H1299 cells were infected with Ad-p53 for the indicated times. Apoptotic cells (sub-G1) were then identified according to DNA content and were counted. (d) Control and catalase-overexpressing $\mathrm{H} 1299$ cells were infected with Ad-p53 for the indicated times. Cell lysates were immunoblotted with the indicated antibodies. (e) PIG3-overexpressing HCT116 p53 ${ }^{-1}$ cells were infected with either Ad-LacZ (white columns) or Ad-catalase (gray columns) for $24 \mathrm{~h}$, and cells were then treated with 0,20 , or $40 \mathrm{~J} / \mathrm{m}^{2}$ UV irradiation. At $48 \mathrm{~h}$ post irradiation, apoptotic cells (Sub-G1) were analyzed. (f) PIG3-overexpressing HCT116 p53 ${ }^{-1-}$ cells were infected with either Ad-LacZ or Ad-catalase for $24 \mathrm{~h}$, and the cells were then untreated or treated with $10 \mathrm{~J} / \mathrm{m}^{2} \mathrm{UV}$ irradiation for the indicated times. Cell lysates were immunoblotted with the indicated antibodies. Results in a-c and $\mathbf{e}$ are shown as mean \pm S.E.M. $(n=3) .{ }^{*} P<0.05 ;{ }^{* \star} P<0.01$

Figure 5 The direct binding of p53 and p53R2 to catalase was visualized by BiFC imaging before and after UV irradiation. (a and $\mathbf{b})$ U2OS cells were co-transfected with either the combination of $\mathrm{p} 53-\mathrm{VN} / \mathrm{catalase}-\mathrm{VC}(\mathrm{A})$ or $\mathrm{p53R2-VN/catalase-VC}$ (b) and untreated (CTL) or treated with $50 \mathrm{~J} / \mathrm{m}^{2} \mathrm{UV}$. BiFC fluorescence was obtained at $2 \mathrm{~h}$ after UV radiation. (c) Fold inductions of the BiFC-positive cells after UV irradiation are indicated to quantify the UV effects on protein interactions. The fold inductions of BiFCpositive cells after the UV treatment were indicated as means \pm s.e.m. of CTL. ${ }^{*} P<0.01$. (d) After either VN-p53 and VC-catalase or VN-p53R2 and VC-catalase were expressed in U2OS cells, time-lapse images of single cells were captured with 5-min interval for up to $2 \mathrm{~h}$ after UV irradiation. (e) To quantify the changing p53/catalase (upper panel) and p53R2/catalase (lower panel) BiFC signals, fluorescence intensities of 14 individual cells were measured using an automated intensity recognition feature of the imaging analysis system. (f) Time-course changes of BiFC signal intensities in individual cells were integrated by statistical analysis as a function of mean values 
PIG3-dependent apoptosis after UV irradiation. Thus, after DNA damage, p53-dependent suppression of catalase activity can regulate overall cellular ROS levels, leading to apoptosis induction. This regulation is biologically important because the magnitude and duration of p53 activity is a critical determinant of cell fate via regulation of ROS levels, which have a significant impact on cell growth, survival, and tumorigenesis. $^{33}$

Another important finding is that the antioxidant function of p53 is derived from the p53R2-catalase pathway, which maintains low ROS levels under physiological conditions. At physiological levels, p53 has a subtle but vital function in maintaining ROS at nontoxic levels through transactivation of a series of genes, including glutathione peroxidase (GPX1), sestrin family members SESN1 and SESN2, ${ }^{14}$ aldehyde dehydrogenase (ALDH4A1), ${ }^{34}$ TP53-induced glycolysis and apoptosis regulator (TIGAR), ${ }^{17}$ TP53-induced nuclear protein 1 (TP53INP1), ${ }^{20}$ and mitochondrial SOD2 (MnSOD) expression. ${ }^{35}$ p53 can also repress the expression of $\mathrm{MnSOD}^{35}$ and $\mathrm{Nrf}^{36}$ and subsequently modulate ROS levels. We found that p53 knockdown increased ROS levels in U2OS and RKO cells, whereas p53 knockdown decreased ROS generation in HCT116 cells. However, the expression patterns of p53-dependent antioxidant genes were similar among p53-depeleted U2OS, RKO, and HCT116 cells, implying that these antioxidant genes might not be contributing to p53's role in regulating ROS levels under no stress or low stress. Importantly, our finding of an inverse correlation between catalase activity and ROS levels in p53-deficient U2OS, RKO, and HCT116 cells raised the possibility that a physiological level of p53 might modulate ROS generation through the regulation of catalase activity. However, because our results showed that hyperphysiological levels of p53 suppressed catalase activity, we enquired why p53 knockdown paradoxically suppressed catalase activity in U2OS and RKO cells. p53 deficiency led to a decrease in levels of catalase in rat retina cells, ${ }^{23}$ whereas p53 did not affect the expression of catalase in human cells. ${ }^{15}$ Our observations that both p53 overexpression and p53 knockdown did not affect catalase expression indicate that the different catalase activities among the p53-deficient HCT116, U2OS, and RKO cells are independent of catalase transcription.

We elucidated the mechanism by which p53-knockdown regulates catalase activity and identified an important role for p53R2, a p53-downstream target, in upregulating catalase activity in unstressed p53-proficient cells. Physiological levels of p53 powerfully negatively regulated intracellular ROS levels via this regulation. Previous reports showed that p53R2 possesses catalase activity. ${ }^{26}$ p53R2, however, exerts its catalase activity through p53R2/catalase protein-protein interactions because p53R2 directly interacts with catalase, leading to an increase in catalase activity in vitro. Expression of a deletion mutant of p53R2 (R2), which does not interact with catalase, had no effect on either catalase activity or ROS levels. p53R2 has been reported to be induced by genotoxic stress in a p53-dependent manner. ${ }^{24,37}$ Our observation that the basal expression of p53R2 in p53-proficient cells is significantly higher than in p53-deficient cells, and that the depletion of endogenous p53 leads to a significant decrease in p53R2 expression, indicates that physiological levels of p53

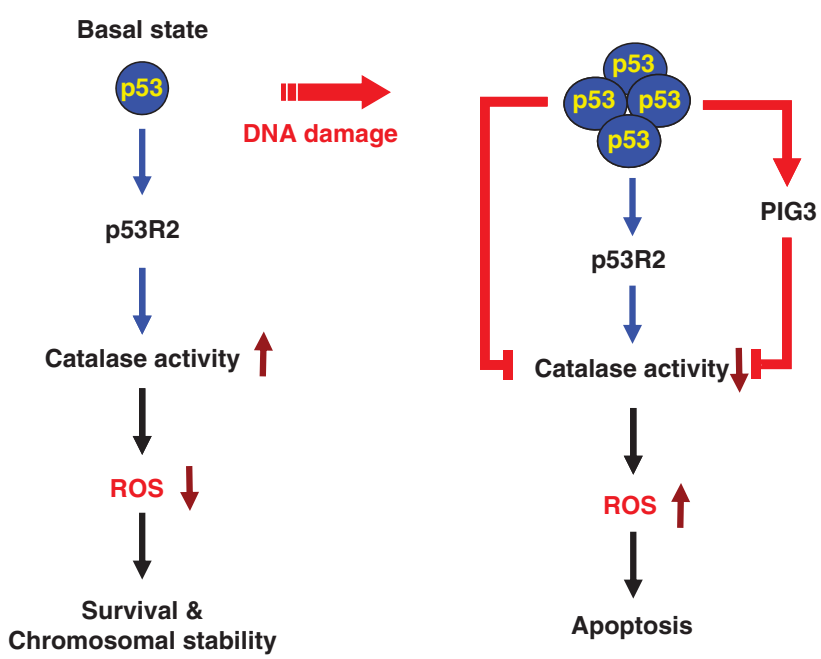

Figure 7 Model of p53-mediated ROS regulation. In the basal state, the p53p53R2 pathway increases catalase activity, leading to a decrease in ROS levels. After DNA damage, however, p53 cooperates with PIG3 to lower catalase activity, causing an increase in ROS accumulation

are sufficient for upregulation of p53R2 in unstressed cells. In normal and unstressed conditions, the subcellular localization of p53 is mainly nuclear, ${ }^{38}$ and both p53R2 and catalase are present in the cytosol. Thus, basal levels of p53 may upregulate catalase activity through p53R2. Indeed, we found that knockdown of endogenous p53 in unstressed cells resulted in a significant decrease in catalase activity, which was associated with decreased binding of p53R2 to catalase. p53R2 expression restored catalase activity in p53 knockdown cells, and consequently, ROS levels were reduced to basal levels. These observations imply that the increased catalase activity induced by p53R2 is probably the main antioxidant function of $p 53$. Our data also established that mutated p53R2 (V115L) was not sufficient to increase catalase activity; ectopic expression of wild-type p53R2, but not mutant p53R2, resulted in increased catalase activity and decreased ROS levels in U2OS, RKO, and HCT116 cells. Because HCT116 cells contain mutated p53R2 (V115L), ${ }^{27}$ p53R2 downregulation did not affect catalase activity in these cells. These results explain why p53 knockdown led to increased catalase activity in HCT116 cells, in contrast to U2OS and RKO cells.

Collectively, our findings clearly demonstrate that p53 regulates ROS levels through direct protein-protein interactions, although p53 is widely accepted to produce opposing effects on ROS levels through the transcriptional induction of prooxidant and antioxidant genes. These results add another layer of complexity to p53-mediated regulation of ROS. We propose a dynamic model for the upregulation and downregulation of ROS production by $\mathrm{p53}$, and its downstream targets p53R2 and PIG3 (Figure 7). Under normal conditions and conditions of mild stress, p53 maintains catalase activity through p53R2, thereby ensuring that ROS levels remain low and control chromosomal stability. Under severe genotoxic stress conditions, high levels of p53 and the pro-apoptotic protein, PIG3, significantly reduce catalase activity and thereby shift the intracellular environment toward oxidative conditions to induce apoptotic cell death. Thus, depending on 
the transcriptional activation of specific downstream target genes and the specific interacting partners, p53 has either prooxidant or antioxidant functions. Given the complex interactions among p53, ROS, and cancer, 1,39,40 our findings should have a major impact on clarifying the molecular pathways that regulate chromosome stability and cancer progression.

\section{Materials and Methods}

Materials. Reagents were obtained from the following sources: antibodies to catalase, p53, p53-HRP, PIG3, and p53R2, from Santa Cruz (Santa Cruz, CA, USA); anti-cleaved caspase-3 and anti-cleaved caspase-7, from Cell Signaling; (Beverly, MA, USA) antibody to the V5 tag, from Invitrogen (Carlsbad, CA, USA); antibody to $\alpha$-tubulin, from NeoMarker (Rocklin, CA, USA); anti-rabbit IgG, and anti-goat IgG, from R\&D Systems (Minneapolis, MN, USA); anti-mouse IgG, from Upstate (Lake Placid, NY, USA); peroxidase-conjugated anti-goat, anti-rabbit, and anti-mouse secondary antibodies, from Jackson ImmunoResearch Laboratories (West Grove, PA, USA); anti-PMP70, hydrogen peroxide, poly-L-lysine, neomycin, and propidium iodide, from Sigma-Aldrich (St. Louis, MO, USA); protease inhibitor cocktail, from Roche (Mannheim, Germany); Amplex Red catalase assay kit and 5-(and-6)-chloromethyl-2' , 7'-dichlorodihydrofluoescein diacetate, acetyl ester (CM$\mathrm{H}_{2} \mathrm{DCFDA}$ ), from Molecular Probes (Carlsbad, CA, USA); protein G-Sepharose beads, from GE Healthcare (Milwaukee, WI, USA); IMDM (Iscove's modified Dulbecco's medium), EMEM (Eagle's minimum essential medium), RPMI 1640 medium, McCoy's 5A medium, penicillin-streptomycin (PS), and trypsin, from Gibco-BRL (Gaithersburg, MD, USA); and fetal bovine serum (FBS), from Cambrex (East Rutherford, NJ, USA).

Cell culture. The human colon carcinoma cell lines HCT116 and HCT116

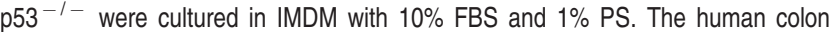
carcinoma cell line RKO was grown in EMEM with 10\% FBS and 1\% PS. The human osteosarcoma cell lines U2OS and Saos-2 were cultured in McCoy's $5 \mathrm{~A}$ medium with $15 \%$ FBS and $1 \%$ PS. The human lung carcinoma cell lines, $\mathrm{NCl}$ $\mathrm{H} 460$ and $\mathrm{NCl} \mathrm{H1299}$, and colon carcinoma cell line, SW480, were maintained in RPMI 1640 medium with $10 \%$ FBS and $1 \%$ PS. The human embryonic kidney cell line HEK293T was grown in DMEM with 10\% FBS and 1\% PS. The HCT116 p53 ${ }^{-1-}$ cell line was a gift from Dr. Bert Vogelstein (Johns Hopkins University School of Medicine, Baltimore, MD, USA), and the HEK293T cell line was obtained from the Cornell Institute for Medical Research. All other cell lines were obtained from the American Type Culture Collection (Rockville, MD, USA).

Immunoprecipitation assay and western blot analysis. Cells were rinsed once with ice-cold PBS and lysed in ice-cold NP-40 lysis buffer ( $50 \mathrm{mM}$ Tris$\mathrm{HCl}(\mathrm{pH} 8.0), 150 \mathrm{mM} \mathrm{NaCl}$, and 1\% Nonidet P-40) with one tablet of EDTA-free protease inhibitor cocktail (Roche). The soluble fraction of the cell lysates was isolated by centrifugation at $13000 \times g$ for $20 \mathrm{~min}$ in a microfuge. Supernatants were measured for protein concentration using a detergent-compatible protein assay (Bio-Rad, Hercules, CA, USA), and equal amounts of proteins were separated by $6-15 \%$ SDS-PAGE, followed by electrotransfer onto a polyvinylidene difluoride membrane (Millipore, Bedford, MA, USA). The membranes were blocked for $2 \mathrm{~h}$ with TBS-t ( $10 \mathrm{mM}$ Tris- $\mathrm{HCl}(\mathrm{pH} 7.4), 150 \mathrm{mM} \mathrm{NaCl}$, and $0.1 \%$ Tween-20) containing $5 \%$ non-fat milk at room temperature and then incubated with primary antibodies overnight at $4{ }^{\circ} \mathrm{C}$. The blots were washed four times for $15 \mathrm{~min}$ with TBS-t containing $0.1 \%$ Tween 20 and then incubated for $2 \mathrm{~h}$ with peroxidaseconjugated secondary antibodies $(1: 4000)$ at room temperature. The membranes were washed four more times and developed using an enhanced chemiluminescence detection system (iNtRON Biotech, Gyeonggi-do, Korea). For the immunoprecipitation assay, lysates were precleared with protein G-Sepharose beads before adding the primary antibody for $15 \mathrm{~min}$. After removing protein G-Sepharose by centrifugation, supernant was transferred and incubated with primary antibodies for $16 \mathrm{~h}$ at $4{ }^{\circ} \mathrm{C}$. Twenty microliter of $50 \%$ slurry of protein G-Sepharose beads were added, and the incubation was continued for an additional $1 \mathrm{~h}$. The immunoprecipitates were washed three times with modified RIPA buffer ( $25 \mathrm{mM}$ Tris (pH 7.2), $150 \mathrm{mM} \mathrm{NaCl}, 5 \mathrm{mM} \mathrm{MgCl}, 0.5 \% \mathrm{NP}-40,1 \mathrm{mM}$ $\mathrm{DTT}$, and $5 \%$ glycerol). Immunoprecipitated proteins were denatured in SDS sample buffer, boiled for $5 \mathrm{~min}$, and analyzed by western blotting using the appropriate antibodies.
For the in vitro protein binding assay, purified recombinant catalase was incubated with p53 or PIG3 in NP-40 lysis buffer overnight at $4^{\circ} \mathrm{C}$. After incubation with antibody to p53 or PIG3 overnight at $4^{\circ} \mathrm{C}$, protein G-Sepharose beads were then added. The beads were washed, and the bound immunocomplexes were analyzed by western blotting with anti-catalase antibody.

Expression and purification of recombinant proteins. The p53R2 and PIG3 cDNAs were cloned into the His-pET vector via BamHI and Xhol sites. Recombinant 6His-tagged p53R2 and PIG3 protein was expressed in Escherichia coli BL21 (DE3) cells after induction with $1 \mathrm{mM}$ IPTG for $6 \mathrm{~h}$ in LB-medium at $37^{\circ} \mathrm{C}$. The bacterial cells were collected by centrifugation, resuspended in lysis buffer (20 mM Tris- $\mathrm{HCl}$ (pH 7.9), $500 \mathrm{mM} \mathrm{NaCl}, 5 \mathrm{mM}$ imidazole, $1 \mathrm{mM} \mathrm{NaF}$, and $1 \mathrm{mM}$ PMSF), sonicated, and then centrifuged at $12000 \times \mathrm{g}$ at $4^{\circ} \mathrm{C}$ for $30 \mathrm{~min}$ The recombinant proteins were purified with a Ni-NTA affinity column (Qiagen, Chatsworth, CA, USA), according to the manufacturer's instructions. Recombinant purified p53 protein was obtained from Calbiochem and recombinant purified catalase was purchased from Sigma (St. Louis, MO, USA).

Semiquantitative RT-PCR analysis. RNA extraction was carried out using TRIzol (Invitrogen), according to the manufacturer's instructions. Reverse transcription was performed using a M-MLV RT (Invitrogen). The following primers were synthesized and used for PCR: p53 sense $5^{\prime}$-ATGGAGGAGCCGCAGTCA GATC- $3^{\prime}$ and antisense $5^{\prime}$-TCAGTCTGAGTCAGGCCCTTCT-3'; p53R2 sense $5^{\prime}$-AT GGGCGACCCGGAAAGGCCG-3' and antisense $5^{\prime}$-TTAAAAATCTGCATCCAAGG TGAA- $3^{\prime}$; catalase sense $5^{\prime}$-ATGGCTGACAGCCGGGATCCC- $3^{\prime}$ and antisense 5'-TCACAGATTTGCCTTCTCCCTTG-3'; SESN1 sense 5'-CGACCAGGACGAGGAACTT-3' and antisense $5^{\prime}$-CCAATGTAGTGACGATAATGTAGG-3'; SESN2 sense $5^{\prime}$-ATGATCGTGGCGGACTCCGAG-3' and antisense $5^{\prime}$-TCAGGTCATGTAG CGGGTGATG-3'; GPX1 sense 5'-ATGAACGAGCTGCAGCGGCGC-3' and antisense $5^{\prime}$-CTAGGCACAGCTGGGCCCTTG-3'; ALDH4A1 sense $5^{\prime}$-ATGCTGCTG CCGGCGCCCGC-3' and antisense 5'-TCACTGCATGTACGCGTAGCTC-3'; SOD2 sense $5^{\prime}$-ATGTTGAGCCGGGCAGTGTGC- $3^{\prime}$ and antisense $5^{\prime}$-TTACTTTTTGCAA GCCATGTATCT-3'; TIGAR sense $5^{\prime}$-ATGGCTCGCTTCGCTCTGACTG-3' and antisense $5^{\prime}$-TTAGCGAGTTCAGTCAGTCCAT-3'; Nrf-2 sense $5^{\prime}$-ATGATGGACT TGGAGCTGCCGC- $3^{\prime}$ and antisense $5^{\prime}$-CTAGTTTTCTTAACATCTGGCTT-3'; TP53INP1 sense $5^{\prime}$-ATGTTCCAGAGGCTGAATAAAATG-3' and antisense $5^{\prime}$-TTA GTAATTGTACTGACGCGGGC-3'; GAPDH sense 5'-TGACCACAGTCCATGCC ATC-3' and antisense $5^{\prime}$-TTACTCCTTGGAGGCCATGT-3'.

Plasmid constructs and clones. The cDNA for human wild-type p53 was amplified from GM00637 human fibroblast cells by RT-PCR using the p53 primers $5^{\prime}$-ATGGAGGAGCCGCAGTCAGATCCT-3' (sense) and 5'-GTCTGAGTCAGGCC CTTCTGTC-3' (antisense). The amplified p53 CDNA construct was cloned into the mammalian expression vector pcDNA3.1/V5-His TOPO (Invitrogen) and confirmed by DNA sequencing. The various truncated p53 CDNA fragments (coding for amino acids 1-300, 1-100, 101-393, 101-300, and 301-393) were PCR-amplified using NOVA-Taq polymerase (Genenmed Inc, Seoul, Korea), and the resulting PCR products were cloned into pcDNA3.1/N5-His TOPO.

The cDNA for human p53R2 and PIG3 was amplified from GM00637 human fibroblast cells by RT-PCR using the p53R2 primers, $5^{\prime}$-GAATTCATGGGCGA CCCGGAAAGGC- $3^{\prime}$ (sense) and 5'-AAAATCTGCATCCAAGGTGAA-3' (antisense); and PIG3 primers, 5'-GGTACCATGTTAGCCGTGCACTTTGA-3' (sense) and $5^{\prime}$-GAATTCTCACTGGGGCAGTTCCAGG-3' (antisense); respectively. The amplified p53R2 and PIG3 cDNA constructs were cloned into the mammalian expression vector pcDNA3.1/V5-His TOPO (Invitrogen) and confirmed by DNA sequencing. The full-length p53R2 cDNA and various truncated p53R2 cDNA fragments (coding for amino acids 1-351, 1-160, 1-206, 11-351, and 316-351) were PCR-amplified using NOVA-Taq polymerase (Genenmed Inc), and the resulting PCR products were cloned into the Gateway Entry vector $\mathrm{pENTR/D-TOPO}$ (Invitrogen). The full-length PIG3 cDNA and various truncated PIG3 cDNA fragments (coding for amino acids 1-332, 1-300, 1-250, 1-200, 1-160 and 161-332) were constructed using same procedure. The constructs were checked for integrity by sequencing and then used for transfer of the inserts into plasmid pcDNA-DEST47 (C-terminal GFP tag) (Invitrogen) by Gateway LR reactions.

The CDNA for human wild-type catalase was amplified from GM00637 human fibroblast cells by RT-PCR using the catalase primers $5^{\prime}$-ATGGCTGACAGCCGG GATCCC- $3^{\prime}$ (sense) and 5'-CAGATTTGCCTTCTCCCTTGCC- $3^{\prime}$ (antisense). The amplified catalase CDNA construct was cloned into the mammalian expression 
vector pcDNA3.1/V5-His TOPO (Invitrogen) and confirmed by DNA sequencing. For stable transfection, the catalase expression vector and control vector were transfected into NCl H1299 cells using Lipofectamine 2000 (Invitrogen), according to the manufacturer's instructions. After transfection, the cells were incubated for 5 weeks in complete medium containing $400 \mu \mathrm{g} / \mathrm{ml}$ neomycin, and the clones resistant to neomycin were isolated and analyzed.

Expression of p53, p53R2, and catalase by the adenovirus system. The full-length cDNAs for p53, p53R2, and catalase were cloned into pENTR/D-TOPO vector using a pENTR Directional TOPO cloning kit (Invitrogen). After purification of the plasmids from the transformed $\mathrm{DH} 5 \alpha$ competent cells, the cDNA inserts were transferred to pAd/CMV/V5-DEST vector (Invitrogen) by means of a Gateway system using LR clonase (Invitrogen). The plasmids were purified and digested with Pacl (New England Biolabs, Ipswich, MA, USA). The linearized plasmids $(1 \mu \mathrm{g})$ were then mixed with $3 \mu \mathrm{l}$ of Lipofectamine 2000 (Invitrogen) in $200 \mu \mathrm{l}$ Opti-MEM medium (Invitrogen) and transfected into subconfluent HEK293T cells in $1 \mathrm{ml}$ of Opti-MEM in six-well plates (Iwaki Glass). The HEK293T cells were cultured for 1-2 weeks in DMEM medium containing 10\% FBS and 1\% PS, with replacement of the medium every 2-3 days. When most of the cells had become detached from the plates, the cells and culture medium were harvested together, freeze-thawed twice, and centrifuged to obtain the adenovirus-enriched supernatants. Aliquots of the supernatants were added to fresh HEK293T cells and cultured for 1 week to amplify the adenoviruses. After two to four amplifications, the resulting adenovirus-containing media were used as virus stocks. Viral titers were determined by the plaque-forming assay with HEK293T cells. As a control, $\mathrm{pAd} / \mathrm{CMV} / \mathrm{V} 5-\mathrm{GW} / \mathrm{lacZ}$ vector (Invitrogen) was digested with Pacl and transfected into HEK293T cells, to produce lacZ-bearing adenovirus. Aliquots of the adenovirus-containing media were added to cells and cultured for the appropriate periods for subsequent analyses.

Small-interference RNA knockdown of p53, p53R2, and catalase. Using the small-interference RNA (siRNA) Target Finder Program (Ambion, Austin, TX, USA), siRNA sequences targeting human p53, p53R2, and catalase were designed. The sequences of the 21-bp siRNA duplexes were: p53, $5^{\prime}$-UUAC ACAUGUAGUUGUAGUGGAUGG-3' (sense strand); p53R2, 5'-UGAGUUUGUAG CUGACAGAUU- $3^{\prime}$ (sense strand); and catalase, 5'-UGGAUAUGGAUCACA UACU-3' (sense strand). Control siRNA was purchased from Bioneer (Daejeon, Korea). Cells were transiently transfected with siRNA duplexes using Lipofectamine RNAiMAX (Invitrogen).

Measurement of intracellular ROS levels. Intracellular ROS production was assayed using the fluorochrome marker 5-(and-6)-chloromethyl-2', 7 '-diclorodihydrofluoescein diacetate, acetyl ester (CM- $\left.\mathrm{H}_{2} \mathrm{DCFDA}\right)$ probe (Invitrogen, Molecular Probes). A fresh stock solution of $\mathrm{CM}-\mathrm{H}_{2} \mathrm{DCFDA}$ was prepared in DMSO and diluted to a final concentration of $5 \mu \mathrm{M}$ in $1 \times \mathrm{PBS}$. Cells were washed with $1 \times \mathrm{PBS}$, followed by incubation with $\mathrm{CM}-\mathrm{H}_{2} \mathrm{DCFDA}$ working solution for $30 \mathrm{~min}$ in the dark at $37^{\circ} \mathrm{C}$. The cells were washed twice and resuspended in PBS, and the increase in fluorescence was detected by flow cytometry (FACSCalibur, BD Biosciences, San Diego, CA, USA). We analyzed the data with CellQuest software and used the mean fluorescence intensity to quantify responses. The mean fluorescence of 30000 analyzed cells (corrected for autofluorescence) of each treatment group was taken as a measure of the total ROS load.

Assay for catalase activity. Cells were sonicated in $0.1 \mathrm{M} \mathrm{Tris-} \mathrm{HCl}(\mathrm{pH}$ 7.5) for two 30-s bursts. After centrifugation at $12000 \times \mathrm{g}$ for $20 \mathrm{~min}$, the supernatants were measured for protein concentration using a detergentcompatible protein assay (Bio-Rad), and catalase activity was measured with an Amplex Red catalase assay kit, according to the manufacturer's protocol (Molecular Probes). After incubating the samples with $40 \mu \mathrm{M} \mathrm{H}_{2} \mathrm{O}_{2}$ for $30 \mathrm{~min}$, the remaining $\mathrm{H}_{2} \mathrm{O}_{2}$ was measured to determine the catalase activity. Amplex Red and horseradish peroxidase react with $\mathrm{H}_{2} \mathrm{O}_{2}$ to produce resorufin, a fluorescent compound detectable by spectrophotometry. Standard curves for the enzymatic activity of catalase were determined using purified catalase. Enzyme-specific activity was expressed as units $/ \mathrm{ml}$ of protein, where one unit of catalase activity was defined as $1 \mu \mathrm{mol} \mathrm{H}_{2} \mathrm{O}_{2}$ consumed per min.

Apoptosis assay. Floating and trypsin-detached cells were collected and washed once with ice-cold PBS, followed by fixing in $70 \%$ cold ethanol for $30 \mathrm{~min}$ at $4{ }^{\circ} \mathrm{C}$. The cells were then washed with ice-cold PBS, resuspended in PBS containing propidium iodide $(50 \mu \mathrm{g} / \mathrm{ml})$, RNase A $(100 \mu \mathrm{g} / \mathrm{ml})$, and $0.1 \%$ Triton $\mathrm{X}-100$, and left for $30 \mathrm{~min}$ at room temperature. To analyze apoptosis, hypodiploid DNA (sub-G1) populations were assayed using a FACSCalibur flow cytometer with CellQuest software (Becton Dickinson, Franklin Lakes, NJ, USA). The results represent the means of triplicate determinations in which a minimum of 10000 cells was assayed for each determination. Any sub-G1 populations were counted as apoptotic cells.

Preparation of peroxisomal-free and peroxisomal fraction. Peroxisomal-free and peroxisomal fraction were isolated by using Peroxisome Isolation Kit (PEROX1, Sigma), according to the instructions of the manufacturer. Briefly, U2OS cells were treated with or without $10 \mathrm{~J} / \mathrm{m}^{2} \mathrm{UV}$ irradiation. At $24 \mathrm{~h}$ after UV treatment, cells were harvested and added in peroxisome extraction buffer, and then transfer cell suspension to in a Dounce homogenizer tube and carefully homogenized for 25 strokes using pestle $B$ on ice. Centrifuge tube at $1000 \times g$ for $10 \mathrm{~min}$ at $4^{\circ} \mathrm{C}$. Transfer the supernatant and centrifuge at $2000 \times \mathrm{g}$ for $10 \mathrm{~min}$ at $4^{\circ} \mathrm{C}$. Transfer the supernatant to a new centrifuge tube and centrifuge at $25000 \times g$ for 20 min Transfer the supernatant liquid (peroxisomal-free fraction) to a new tube and collect the pellet (peroxisomal fraction) in a peroxisome extraction buffer.

Immunofluorescence microscopy. U2OS cells were cultured on cover slips coated with poly-L-lysine (Sigma) and were treated with or without $10 \mathrm{~J} / \mathrm{m}^{2}$ UV irradiation. At $24 \mathrm{~h}$ after UV treatment, cells were then washed twice with PBS, fixed in $4 \%$ paraformaldehyde for $10 \mathrm{~min}$, followed by permeabilization with $0.3 \%$ Triton X-100 for $15 \mathrm{~min}$ at room temperature. Next, the cover slips were washed three times with PBS and then blocked with $0.1 \%$ BSA in PBS for $1 \mathrm{~h}$ at room temperature. The cells were double-immunostained with primary antibodies against various proteins overnight at $4^{\circ} \mathrm{C}$, after which the cells were washed with PBS and stained with Alexa Fluor 488- (green fluorescence; Molecular Probes) or Alexa Fluor 594- (red fluorescence; Molecular Probes) conjugated secondary antibodies, as appropriate. After washing, the cells were mounted using Vectashield mounting medium with 4,6-diamidino-2-phenylindole (Vector Laboratories, Burlingame, CA, USA). Fluorescence images were taken using a confocal microscope (Zeiss LSM 510 Meta; Carl Zeiss, Jena, Germany) and Zeiss LSM Image Examiner software (Carl Zeiss).

BiFC analyses. The BiFC assay is based on the complementation of two nonfluorescent receptor molecule fragments that generate a fluorescence signal only when they directly interact in vivo. By fusing cDNAs encoding residues 1-172 (VN173) of Venus to sequences encoding p53 or p53R2, and the C-terminus of Venus (residues 155-238) (VC155) to a sequence-encoding catalase, we generated three different plasmids: p53-VN, p53R2-VN, and catalase-VC. pHAVC155 were kindly provided by Chang-Deng Hu (Purdue University School of Pharmacy, West Lafayette, IN, USA). ${ }^{41}$ U2OS cells were cultivated in $35-\mathrm{mm}$ culture dishes overnight and then cotransfected with the expression vectors (200 ng each) using a Microporator Neon (Invitrogen). At $24 \mathrm{~h}$ post transfection, the cells were exposed to UV radiation $\left(50 \mathrm{~J} / \mathrm{m}^{2}\right)$. Samples were examined under a fluorescence microscope, and the images were captured using a YFP filter set (excitation, $500 \mathrm{~nm}$; dichromic beam splitter, $515 \mathrm{~nm}$; emission, $535 \mathrm{~nm}$ ). Cells producing fluorescent signals after UV irradiation (BiFC signal-positive cells) were counted. For immunofluorescence analyses, cells were fixed with $3.75 \%$ paraformaldehyde in PBS and incubated with anti-GFP N-terminus and antiGFP C-terminus antibodies. The cells were visualized with secondary antibodies conjugated to Alexa Fluor 350 (Invitrogen) or TRITC (Jackson ImmunoResearch Laboratories).

Time-lapse imaging analyses. Cells were transferred to a live cell chamber (Live Cell Instrument, Seoul, South Korea) in growth medium containing $10 \%$ FBS and cotransfected with the BiFC expression vectors ( $300 \mathrm{ng}$ each) using a Microporator Neon (Invitrogen). For the UV radiation experiments, transfected cells were incubated in a humidified chamber at $37^{\circ} \mathrm{C}$ and ambient $\mathrm{CO}_{2}$ levels for $12 \mathrm{~h}$, and then exposed to UV radiation $\left(50 \mathrm{~J} / \mathrm{m}^{2}\right)$. Images were collected at $37^{\circ} \mathrm{C}$ using an Olympus IX-81 microscope. At each time point, a fluorescence image was taken using a YFP filter set. To quantify changes in the BiFC signals, the fluorescence intensities of 15 individual fluorescent cells were measured using an automated intensity recognition feature of the MetaMorph Imaging System (Universal Imaging Corporation, Downingtown, PA, USA). 
Yeast two-hybrid analysis. A yeast two-hybrid screen was performed using a Matchmaker GAL4 Two-Hybrid System 3 (Clontech, Mountain View, CA) following the manufacturer's directions. Saccharomyces cerevisiae strain AH109, containing distinct ADE2, HIS3, lacZ, and MEL1 reporter constructs, was used for the assay. The AH109 strain was transformed with the bait plasmid pGBT9, encoding an in-frame fusion of the GAL4 DNA-binding domain with full-length p53 and PIG3. Transformants were plated onto selective SD medium lacking Trp and incubated for $3-5$ days at $30^{\circ} \mathrm{C}$. Yeast strains containing the bait plasmid were transformed with a prostate CDNA library fused to the GAL4 activation domain in pACT2 vector. Diploids were plated on SD-Leu/-Trp/-His medium, and growing colonies, indicative of a potentially positive interaction between the bait (p53 or PIG3) and prey (library protein), were re-streaked on SD-Leu/-Trp/-His/-Ade plates. Finally, positive clones were replica-plated on maximally selective SD-Leu/Trp/-His/-Ade/X- $\alpha$-gal medium to ensure that the colonies contained the correct phenotype. Plasmid DNA was isolated from positive clones and sequenced to identify the genes encoding the interacting proteins. The sequences were analyzed using the BLAST program available from NCBI.

Statistical analysis. The statistical significance of the difference between mean values was tested using Student's $t$-test $\left({ }^{\star \star} P<0.01 ;{ }^{*} P<0.05\right)$. Data are means \pm S.E.M.

\section{Conflict of Interest}

The authors declare no conflict of interest.

Acknowledgements. This research was supported by the Ministry of Education, Science and Technology funded by the Korea Government (20120001122).

1. Liu B, Chen Y, St Clair DK. ROS and p53: a versatile partnership. Free Radic Biol Med 2008; 44: 1529-1535.

2. Valko M, Rhodes CJ, Moncol J, Izakovic M, Mazur M. Free radicals, metals and antioxidants in oxidative stress-induced cancer. Chem Biol Interact 2006; 160: 1-40.

3. Valko M, Leibfritz D, Moncol J, Cronin MT, Mazur M, Telser J. Free radicals and antioxidants in normal physiological functions and human disease. Int $\mathrm{J}$ Biochem Cell Biol 2007; 39: 44-84.

4. Terada LS. Specificity in reactive oxidant signaling: think globally, act locally. J Cell Biol 2006; 174: 615-623.

5. Giorgio M, Trinei M, Migliaccio E, Pelicci PG. Hydrogen peroxide: a metabolic by-product or a common mediator of ageing signals? Nat Rev Mol Cell Biol 2007; 8: 722-728.

6. Liu $\mathrm{G}$, Chen $X$. The ferredoxin reductase gene is regulated by the $p 53$ family and sensitizes cells to oxidative stress-induced apoptosis. Oncogene 2002; 21: 7195-7204.

7. Macip S, Igarashi M, Berggren P, Yu J, Lee SW, Aaronson SA. Influence of induced reactive oxygen species in p53-mediated cell fate decisions. Mol Cell Biol 2003; 23: 8576-8585.

8. Polyak K, Xia Y, Zweier JL, Kinzler KW, Vogelstein B. A model for p53-induced apoptosis Nature 1997; 389: 300-305.

9. Johnson TM, Yu ZX, Ferrans VJ, Lowenstein RA, Finkel T. Reactive oxygen species are downstream mediators of p53-dependent apoptosis. Proc Natl Acad Sci USA 1996; 93 11848-11852.

10. Donald SP, Sun XY, Hu CA, Yu J, Mei JM, Valle D et al. Proline oxidase, encoded by p53induced gene-6, catalyzes the generation of proline-dependent reactive oxygen species. Cancer Res 2001; 61: 1810-1815.

11. Schmitt CA, Fridman JS, Yang M, Baranov E, Hoffman RM, Lowe SW. Dissecting p53 tumor suppressor functions in vivo. Cancer Cell 2002; 1: 289-298.

12. Vousden KH, Prives C. Blinded by the Light: The Growing Complexity of p53. Cell 2009; 137: 413-431.

13. Matoba S, Kang JG, Patino WD, Wragg A, Boehm M, Gavrilova $\mathrm{O}$ et al. p53 regulates mitochondrial respiration. Science 2006; 312: 1650-1653.

14. Sablina AA, Budanov AV, llyinskaya GV, Agapova LS, Kravchenko JE, Chumakov PM The antioxidant function of the p53 tumor suppressor. Nat Med 2005; 11: 1306-1313.

15. Hussain SP, Amstad P, He P, Robles A, Lupold S, Kaneko I et al. p53-induced up-regulation of MnSOD and GPx but not catalase increases oxidative stress and apoptosis. Cancer Res 2004; 64: 2350-2356.

16. Meiller A, Alvarez S, Drane P, Lallemand C, Blanchard B, Tovey M et al. p53-dependent stimulation of redox-related genes in the lymphoid organs of gamma-irradiated-mice identification of Haeme-oxygenase 1 as a direct p53 target gene. Nucleic Acids Res 2007; 35: 6924-6934.

17. Bensaad K, Tsuruta A, Selak MA, Vidal MN, Nakano K, Bartrons $R$ et al. TIGAR, a p53-inducible regulator of glycolysis and apoptosis. Cell 2006; 126: 107-120.

18. Budanov AV, Sablina AA, Feinstein E, Koonin EV, Chumakov PM. Regeneration of peroxiredoxins by p53-regulated sestrins, homologs of bacterial AhpD. Science 2004; 304: 596-600.

19. Chen W, Sun Z, Wang XJ, Jiang T, Huang Z, Fang D et al. Direct interaction between Nrf2 and p21(Cip1/WAF1) upregulates the Nrf2-mediated antioxidant response. Mol Cell 2009; 34: 663-673

20. Cano CE, Gommeaux J, Pietri S, Culcasi M, Garcia S, Seux M et al. Tumor protein 53-induced nuclear protein 1 is a major mediator of p53 antioxidant function. Cancer Res 2009; 69: 219-226.

21. Hu W, Zhang $C$, Wu R, Sun $Y$, Levine A, Feng Z. Glutaminase 2, a novel p53 target gene regulating energy metabolism and antioxidant function. Proc Natl Acad Sci U S A 2010; 107: 7455-7460

22. Chelikani P, Fita I, Loewen PC. Diversity of structures and properties among catalases. Cell Mol Life Sci 2004; 61: 192-208.

23. O'Connor JC, Wallace DM, O'Brien CJ, Cotter TG. A novel antioxidant function for the tumor-suppressor gene p53 in the retinal ganglion cell. Invest Ophthalmol Vis Sci 2008; 49: 4237-4244.

24. Tanaka H, Arakawa H, Yamaguchi T, Shiraishi K, Fukuda S, Matsui K et al. A ribonucleotide reductase gene involved in a p53-dependent cell-cycle checkpoint for DNA damage. Nature 2000; 404: 42-49.

25. Bourdon A, Minai L, Serre V, Jais JP, Sarzi E, Aubert S et al. Mutation of RRM2B, encoding p53-controlled ribonucleotide reductase (p53R2), causes severe mitochondrial DNA depletion. Nat Genet 2007; 39: 776-780.

26. Xue L, Zhou B, Liu X, Wang T, Shih J, Qi C et al. Structurally dependent redox property of ribonucleotide reductase subunit p53R2. Cancer Res 2006; 66: 1900-1905.

27. Yamaguchi T, Matsuda K, Sagiya Y, Iwadate M, Fujino MA, Nakamura $Y$ et al. p53R2dependent pathway for DNA synthesis in a p53-regulated cell cycle checkpoint. Cancer Res 2001; 61: 8256-8262.

28. Amstad P, Peskin A, Shah G, Mirault ME, Moret R, Zbinden I et al. The balance between $\mathrm{Cu}, \mathrm{Zn}$-superoxide dismutase and catalase affects the sensitivity of mouse epidermal cells to oxidative stress. Biochemistry 1991; 30: 9305-9313.

29. Hu CD, Kerppola TK. Simultaneous visualization of multiple protein interactions in living cells using multicolor fluorescence complementation analysis. Nat Biotechnol 2003; 21: 539-545.

30. Lee Y, Lee J, Kwon I, Nakajima Y, Ohmiya Y, Son GH et al. Coactivation of the CLOCKBMAL1 complex by CBP mediates resetting of the circadian clock. J Cell Sci 2010; 123 (Pt 20): 3547-3557.

31. Unger T, Sionov RV, Moallem E, Yee CL, Howley PM, Oren M et al. Mutations in serines 15 and 20 of human p53 impair its apoptotic activity. Oncogene 1999; 18: 3205-3212.

32. Hafsi H, Hainaut P. Redox control and interplay between p53 isoforms: roles in the regulation of basal p53 levels, cell fate, and senescence. Antioxid Redox Signal 2011; 15: 1655-1667.

33. Ladelfa MF, Toledo MF, Laiseca JE, Monte M. Interaction of p53 with tumor suppressive and oncogenic signaling pathways to control cellular reactive oxygen species production. Antioxid Redox Signal 2011; 15: 1749-1761.

34. Yoon KA, Nakamura Y, Arakawa H. Identification of ALDH4 as a p53-inducible gene and its protective role in cellular stresses. J Hum Genet 2004; 49: 134-140.

35. Pani G, Galeotti T. Role of MnSOD and p66shc in mitochondrial response to p53. Antioxid Redox Signal 2011; 15: 1715-1727.

36. Faraonio R, Vergara P, Di Marzo D, Pierantoni MG, Napolitano M, Russo T et al. p53 suppresses the Nrf2-dependent transcription of antioxidant response genes. J Biol Chem 2006; 281: 39776-39784.

37. Lin ZP, Belcourt MF, Cory JG, Sartorelli AC. Stable suppression of the R2 subunit of ribonucleotide reductase by R2-targeted short interference RNA sensitizes p53(-/-) HCT116 colon cancer cells to DNA-damaging agents and ribonucleotide reductase inhibitors. J Biol Chem 2004; 279: 27030-27038.

38. O'Brate A, Giannakakou P. The importance of p53 location: nuclear or cytoplasmic zip code? Drug Resist Updat 2003; 6: 313-322.

39. Oberdoerffer $P$, Sinclair DA. The role of nuclear architecture in genomic instability and ageing. Nat Rev Mol Cell Biol 2007; 8: 692-702.

40. Finkel T, Serrano M, Blasco MA. The common biology of cancer and ageing. Nature 2007; 448: $767-774$

41. Hu CD, Grinberg AV, Kerppola TK. Visualization of protein interactions in living cells using bimolecular fluorescence complementation (BiFC) analysis. Curr Protoc Cell Biol 2006 Chapter 21: Unit 213 